Alma Mater Studiorum - Università di Bologna DEPARTMENT OF ECONOMICS

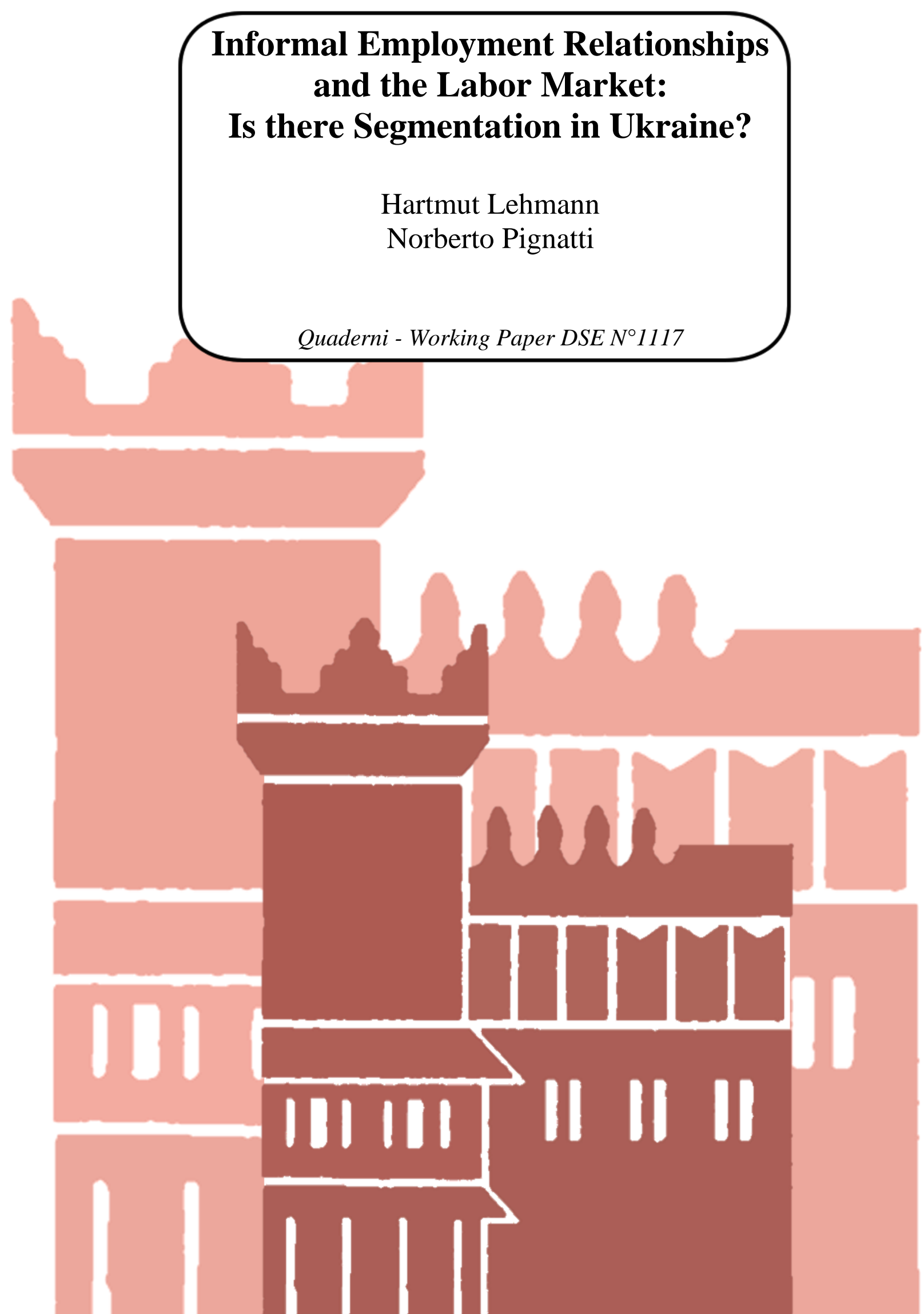




\title{
Informal Employment Relationships and the Labor Market: Is there Segmentation in Ukraine? ${ }^{1}$
}

\author{
Hartmut Lehmann (University of Bologna, IZA and DIW) \\ Norberto Pignatti (International School of Economics at Tbilisi State University and IZA)
}

January 2018

\begin{abstract}
One of the most important factors that determine individuals' quality of life and wellbeing is their position in the labor market and the type of jobs that they hold. When workers are rationed out of the formal segment of the labor market against their will, i.e., the labor market is segmented, their quality of life is limited, and their wellbeing is reduced. When they can freely choose between a formal or informal employment relationship, i.e., the labor market is integrated, their wellbeing can reach high levels even in the presence of informal employment. We, therefore, test whether the Ukrainian labor market is segmented along the formal-informal divide, slicing the data by gender and age. The analysis that we perform consist in the analysis of short-term and medium-term transitions between five employment states, unemployment and inactivity. We also analyze wage gaps of mean hourly earnings and across the entire hourly earnings distribution, controlling for time-invariant unobserved heterogeneity. According to our results segmentation is present for dependent employees: for a large part of informal employees informal employment is used as a waiting stage to enter formal salaried employment and is not voluntarily chosen. As far as self-employment is concerned the evidence is mixed regarding in the Ukrainian labor market. This heterogeneity in outcomes implies that not all informal work is associated with a low quality of life and reduced wellbeing in post-transition economies.
\end{abstract}

JEL Classification: J31, J40, P23

Keywords: Informal Employment, Labor Market Segmentation, Transition Economies, Ukraine

\footnotetext{
${ }^{1}$ The authors are grateful to Randall Akee, Sumon Bhaumik, Tilman Brück, Tom Coupé, Gary Fields, Yuriy Gorodnichenko, Olga Kupets, William Maloney, Alexander Muravyev, Olena Nizalova, Hanna Onyshchenko, Pavlo Prokopovich, Anzelika Zaiceva, and participants of the IZA-Worldbank Workshop "The Informal Economy and Informal Labor Markets in Developing, Transition and Emerging Economies" in Bertinoro, Italy in January 2007, of the Conference of the Scottish Economic Association in Perth in April 2007, of the IZA-World Bank conference on development and the labor market in Bonn, Germany in June 2007, the conference "People matter: Quality of Life and Population Wellbeing in Post-Transition Economies" in Kyiv, Ukraine in September 2017 as well as to seminar audiences at DIW, Bologna and KSE for comments and suggestions on earlier versions of the paper.
} 


\section{Informal Employment Relationships and the Labor Market: Is there Segmentation in Ukraine?}

\section{Introduction}

The quality of life of individuals depends on many factors, very prominent among them individuals' position in the labor market and the kind of jobs that they hold. For many social scientists stable employment in formal jobs is associated with life satisfaction and a high quality of life. Such a view is, however, not universal in the economics literature on formal and informal employment in developing and post-transition countries. Some authors put forth the proposition that conditional on workers' characteristics many workers have higher utility when they are informal wage employees or informally self-employed. Those who consider formal jobs as superior along many dimensions perceive the labor market as segmented. In this view, formal jobs are good jobs since they provide high wages, good working conditions, employment protection and insurance against unforeseen health or employment shocks. However, because of labor market institutions and policies the access to good jobs is rationed and some workers are unlucky and have to queue in informal jobs, which do not have any of the good characteristics of formal jobs, before they can enter the formal sector. A competing view sees the labor market as integrated, with individuals selecting themselves into that segment of the labor market that generates highest utility for them. Understanding the nature of jobs along the formal-informal divide is, therefore, important if one wants to assess social welfare and subjective wellbeing in developing and post-transition countries.

The empirical literature on labor market segmentation usually proposes two types of "tests", the analysis of transition probabilities between labor market states that include informal employment, as well as the analysis of formal-informal wage gaps at the mean, and in more recent studies, across the entire earnings distribution. When we discuss this literature regarding post-transition countries below, we will see that most of the studies are plagued by relatively poor data that limit the scope of the analysis or that require unrealistic assumptions. This paper uses a data set that is less limiting, the Ukrainian 
Longitudinal Monitoring Survey (ULMS). ${ }^{2}$ It allows us to make precise distinctions between different types of informal employment and it has a panel dimension that straddles the years 2003 to $2007 .{ }^{3}$ This latter feature enables us to establish medium-term effects of transitions between different types of employment and other labor market states as well as provide precise point estimates of fixed effects wage gap regressions. Most of the literature on labor market segmentation in post-transition countries uses two-year panels and is not able to distinguish between voluntary and involuntary informal employment relationships, something we are able to do with the ULMS data. Our analysis will also provide a comparative perspective by contrasting our results for Ukraine with the results presented in the literature for other post-transition countries. Given the high quality of the ULMS data our paper will contribute to this literature in a substantial way for at least two reasons. First, we explore whether labor market segmentation plays out differently for female and male workers in Ukraine. Second, in spite of a relatively short panel, new methods in fixed effects quantile regressions enable us to provide consistent estimates of formal-informal wage differentials across the entire earnings distribution in the presence of unobserved heterogeneity.

Thus far we only briefly sketched the two main schools of thought regarding the role of informal employment. In the next section, we, therefore, discuss these two main paradigms in the literature on informality and informal employment and labor market segmentation plus a third paradigm in more detail. This is followed by a survey of the empirical literature testing for labor market segmentation, with an exclusive focus on the research related to post-transition economies. The fourth section then presents the ULMS data, gives some descriptive statistics and discusses our research strategy. In section five we show our main results, highlighting estimated transition probabilities between labor market states that include different types of informal employment as well as estimates of wage gap regressions

\footnotetext{
${ }^{2}$ For a detailed description of the ULMS see Lehmann, Muravyev and Zimmermann (2012).

${ }^{3}$ In this paper we only use three waves of the ULMS, 2003, 2004 and 2007, when the Ukrainian economy experienced continuous strong growth. We exclude the fourth wave (2012) from the analysis since it was collected after the Great Recession hit Ukraine very hard.
} 
and quantile wage gap regressions that include fixed effects. The final section discusses our results in the light of the literature and gives some conclusions.

\section{The literature on informality and informal employment: theoretical considerations}

The existence of the informal segment of the labor market alongside the formal sector and the reasons posited for its existence have given rise to several paradigms in the literature. One key question in the labor market literature for developing countries is whether informal employment or self-employment reflects voluntary choice or is involuntary due to rationing in the labor market (Guasch 1999). The traditional dualistic view, going back to Harris and Todaro (1970), sees the informal segment as the inferior sector, the option of last resort. Due to barriers to entry, minimum wages, unions or other sources of segmentation, formal jobs are rationed. Workers in the informal sector are crowded out of the formal sector involuntarily, their wage being less than that in the formal sector. ${ }^{4}$ For example, an increase in the statutory wage in the formal sector will reduce formal employment but lead to a lower informal wage and higher informal employment. During a recession informal employment and output expands because formal employment is reduced, while the informal labor market clears. In this view labor market segmentation between formality and informality is the defining feature of the labor market.

In contrast, in a competitive labor market one would expect workers to be able to move freely between occupations, and for wages (broadly interpreted) to equalize accordingly. In this view the formal and informal sectors of the labor market are not segmented, but integrated. Voluntary choice regarding jobs and particular attributes of these jobs, such as flexible hours, working as a self-employed and being one's own boss as a micro-entrepreneur, and not valuing social security benefits and/or future pension benefits, can be the reasons for remaining in or moving into informal employment (Maloney

${ }^{4}$ In this school of thought, formal sector jobs not only command higher wages but also provide employment protection and fringe benefits that are both absent with informal sector jobs. 
1999, 2004; Cunningham and Maloney 2001). Here, contrary to the segmentation case, formal and informal employment are not necessarily negatively correlated over the business cycle.

Segmentation and integration of the formal and informal labor market segments are two polar views regarding the interaction of formality and informality. However, as suggested by Tokman (1986) and Fields (1990), it is possible that these features co-exist in the same labor market segment, given the heterogeneity of informal workers. Tokman and Fields envision two segments: an 'easy-entry' informal sector, which constitutes the involuntary segment, and an 'upper-tier' informal sector, where barriers of entry persist and in which participation is voluntary. Hence, the labor market is divided into a formal sector, a 'disadvantaged' subsistence-level informal sector and a voluntary informal sector, where we can find salaried workers but also micro-entrepreneurs.

In recent years, this lay-out of the presented paradigms has been questioned as far too schematic and polar. For example, several contributions in Guha-Kasnobis, Kanbur and Ostrom (2006) take issue with a dichotomous view of labor markets in developing countries along the formal-informal divide. For example, Chen (ibidem) sees exclusively formal and informal firms and employment as polar cases and stresses that there exists a continuum between these poles where most workers and firms locate. Guha-Kasnobis, Kanbur and Ostrom in their introductory remarks highlight that the terms formal and informal are rather metaphors that have connotations that are context-dependent. A somewhat different line of critical reasoning is taken by some empirical labor economists who argue that once sound econometric techniques are employed evidence confirming labor market segmentation disappears or labor market segmentation becomes at best marginal. These authors essentially claim that informalformal wage gaps across the distribution are driven by selection: once researchers take account of unobservable characteristics of salaried workers or of the self-employed these gaps for the most part disappear or become tiny (see, e.g., Bargain and Kwenda, 2011, 2014). This last point is not confirmed in the Ukrainian case even as we employ the most up-to-date econometric model of fixed effects quantile regressions as we shall demonstrate in the results section. The presented paradigms strike us, therefore, 
as still a useful point of departure in the understanding of the role of informal employment in the labor market.

\section{Defining and operationalizing informal employment and the empirical literature on testing} labor market segmentation in post-transition economies

\subsection{Defining and operationalizing informal employment}

Before we present the literature that tests labor market segmentation in post-transition economies we need to briefly discuss how we define informality and informal employment in this study and which questions from the ULMS survey we use to establish voluntary and involuntary informal employment. The definition of informality is a very complex issue as nicely exposited, for example, in chapter 1 of Perry et al. (2007) and in Kanbur (2009). There are essentially two broad groups of definitions in the literature: the "productivity-based" and the "legalistic" or social protection definitions. The first one characterizes informality in the labor market by job characteristics: non-professional self-employed, unskilled workers, persons in marginal jobs, domestic and family workers and workers in small firms with up to 5 employees are all considered informal workers. The "legalistic" or social protection definition considers non-compliance with the regulations of the state regarding labor laws and social security systems as the defining characteristic of informality. Dependent workers who, in order to avoid paying taxes, do not pay social security and/or pension contributions or are prevented from doing so by their employers are considered informal. The self-employed who do not register their activities with the state are also considered informal.

We use the "legalistic" definition throughout in this paper since we find that using a "productivity-based" concept when defining informal or formal sectors would be rather misleading, certainly in post-transition countries. For example, to take all non-professional self-employed or workers in micro firms as belonging to the informal sector might be appropriate in a developing country context but often introduces large measurement error in post-transition countries. Our early study on 
informal employment in Ukraine (Lehmann and Pignatti 2007), for example, shows that in 2003 and 2004 a large part of the non-professional self-employed are formal workers and that more than 60 percent of informal salaried workers are employed in non-micro firms. Hence, using a productivitybased concept of informality can lead to massive measurement error. Below, we will present the concrete questions answered by respondents that allow us to pin down informal employment using the legalistic definition. Having a precisely defined measure of informal employment is an important premise of rigorous testing of labor market segmentation since it avoids the "fuzziness" that according to $\operatorname{Kanbur}(2009,2015)$ many studies are plagued by.

Turning to the relevant questions in the ULMS survey allows us to operationalize informal employment relationships and their voluntary or involuntary nature. We use the information we have for the reference weeks in the main job $b^{5}$ and define an employment relationship as formal if employees answer the following question by choosing option 1 , informal if they choose option 2 :

Tell me, please, are you officially registered at this job, that is, are you on a work roster, work agreement or contract?

\section{Registered 2. Not Registered.}

For the self-employed we use a similar question:

Is your activity registered?

1. Yes 2. No

The self-employed decide for themselves whether to register their activity or not. We, therefore, think of all informal self-employed as voluntary informal self-employed. For employees we elicit the additional information about the (in-) voluntary nature of their informal job by asking the following question:

Why are you not officially registered at this job?

1. Employer does not want to register me.

2. I do not want to register.

\footnotetext{
${ }^{5}$ According to the ULMS data only a small fraction of workers has a secondary job: in 2003, 2004 and $20072.23 \%, 2.4 \%$ and $1.65 \%$ respectively.
} 


\section{Both.}

Answer 1 classifies a person in her/his main job as involuntary informal employed, answers 2 and/or 3 as voluntary informal employed.

We now turn to the two main approaches in the empirical literature that test labor market segmentation. One method looks at the question whether there is a wage gap between similar workers who have formal and informal employment relationships. The second method looks at mobility between labor market states to assess whether there are barriers between formal and informal segments of the labor market or whether workers can move freely between these segments. We exclusively focus on empirical studies dealing with post-transition economies.

\subsection{The empirical literature on labor market segmentation in post-transition economies}

\subsubsection{Wage gap analysis}

We start off with the evidence on the wage gap along the formal-informal divide, which is very limited for post- transition countries. Evidence, which is based on cross-sectional data, is severely biased because of selection problems: unobserved characteristics such as ability or motivation might be important determinants of an individual's selection into a formal or informal job. Fixed effects estimates of wage differentials based on longitudinal data control for unobserved heterogeneity as long as the unobserved characteristics are time-invariant and equally remunerated across jobs. Even though the use of longitudinal data has its own problems when assessing wage gaps (Solon 1988), we report on two studies that employ panel data: Pagés and Stampini (2009) and Lehmann and Pignatti (2007), since they provide relatively reliable estimates of formal-informal wage gaps.

Pagés and Stampini analyze wage differentials in three post-transition countries: Albania, Georgia and Ukraine. They use cross-sectional and fixed effects regressions and difference-indifferences analysis to investigate whether there is a premium for formal jobs or for informal jobs in the three countries, distinguishing between skilled and unskilled workers. The cross-sectional results 
establish a premium in informal jobs in Georgia for the unskilled and a formality premium in Ukraine across both skill levels. These results are overturned when longitudinal data are employed in the estimations. In Georgia the authors establish a wage gain for workers who change from formal to informal jobs, and this wage gain is larger for skilled workers than for their unskilled counterparts. In Ukraine, on the other hand, the formality premium disappears when unobserved characteristics are controlled for. According to the authors, in Ukraine the formal wage premium comes about because higher ability workers select themselves into formal jobs and not because jobs are of higher quality in the formal sector. In Georgia, they establish the astonishing results that higher ability workers seem to select themselves into informal jobs. Finally, the results for Albania show no premium independent of the estimation method used. So, the evidence of Pagés and Stampini seems to point to integrated labor markets in the three analyzed post-transition countries.

The paper by Lehmann and Pignatti (2007), our early study on informal employment in Ukraine, uses the waves 2003 and 2004 of the ULMS to analyze informal-formal wage gaps. Like Pagés and Stampini, we estimate fixed effects and difference-in-differences regressions, dividing employment into five mutually exclusive states: formal salaried, voluntary informal salaried, involuntary informal salaried, formal self-employment and informal self-employment. The latter category includes informal entrepreneurs whose number in the sample is small, though. We use the same division of employment in this paper.

Relative to the default category of formal salaried workers, the fixed effects regressions of our early research show positive wage differentials in Ukraine for voluntary informal salaried workers, formal self-employment and informal self-employment, while there is no significant difference in the wages of formal salaried and involuntary informal salaried workers. The difference-in-differences estimates of log hourly real earnings for movers versus stayers confirm the fixed effects regression results. There is no difference in the growth rates of hourly wages for formal salaried and involuntary informal salaried workers; however, for the other three employment categories hourly wages grow more than for formal salaried workers. This growth differential is particularly large for the informally self- 
employed. In this early research we did not estimate formal-informal wage gaps across the entire distribution, though.

Summarizing the results of our early study and the research by Pagés and Stampini on the Ukrainian labor market, the evidence seems to suggest that once one controls for self-selection into an employment state the wage differential between the formal and informal sector disappears. The results also imply that the informal sector is in itself segmented since we find a positive wage premium for those who voluntarily choose informality, i.e., the voluntary informal salaried and the informal selfemployed. However, given that we have one more wave of data and given the advances in fixed effects quantile regression even with short panels, our new study provides more solid evidence regarding the question of labor market segmentation in Ukraine.

The outcomes presented by Pagés and Stampini and Lehmann and Pignatti for Ukraine are roughly confirmed by more recent work on Russia by Lehmann and Zaiceva (2013) who employ OLS and fixed effects estimation of the informal-formal wage gap. The OLS estimates establish a wage penalty for informal employees and an insignificant wage differential for informal self-employed and entrepreneurs once sector and occupation are controlled for. The outcome for informal employees is, however, not an expression of differences in job qualities as the fixed effects estimates do not point to a significant wage differential; so, once the authors control for time-invariant unobserved characteristics such as innate ability and motivation, informal employees are remunerated similarly to formal employees. On the other hand, like in the Ukrainian labor market, the informal self-employed and entrepreneurs receive a wage premium even when self-selection is taken into account.

Lehmann and Zaiceva (2013) provide additional information regarding labor market segmentation by estimating the hourly wage gap over the entire wage distribution, using pooled quantile regressions. Low skilled informal employees experience a statistically significant and economically meaningful wage penalty while informal employees with high skills have the same wages as their formal counterparts. Hence their quantile regression results tell us that for highly skilled informal employees, having a share of roughly $30 \%$ of informal salaried employment, the labor market is integrated; in 
contrast, the majority of salaried informal workers, who have lower skills, experience a significant wage gap and seem thus confronted with a segmented labor market in Russia. When the self-employed and entrepreneurs are added to dependent employees the picture changes substantially. Now the informal sector seems segmented in the sense of Tokman (1986) and Fields (1990) since we have a lower part of the distribution with wage penalties (a free entry lower tier) and an upper part with positive wage differentials (a rationed upper tier).

\subsubsection{Mobility analysis}

How mobile are workers in labor markets of post-transition countries across the formal-informal divide? Researchers use transition probability matrices in various forms to approach this question. They look at simple $P[i, j]$ matrices where $i$ and $j$ are the origin and destination states respectively and $P$ is the estimated probability of movement between these two states, assuming a Markov process. Let i represent informal employment and $\mathrm{j}$ formal employment. When $\mathrm{P}[\mathrm{i}, \mathrm{j}]>>\mathrm{P}[\mathrm{j}, \mathrm{i}]$, this seems to imply that there is a much higher likelihood of flowing from informal into formal employment than vice versa. Hence workers supposedly queue in the informal sector to enter formal employment, which is taken as evidence of labor market segmentation. This simple comparison of flows has been criticized insofar as it does not take into account the different turnover rates across labor market states. If most of the workforce is employed formally and the informal sector is comprised of only a small share of the workforce it is just a statistical artifact that the transition rate from informal to formal employment is a multiple of the transition rate from formal to informal employment. To account for this artifact researchers produce transition matrices that are adjusted for the relative size of a state and for its capacity to generate vacancies. The studies by Lehmann and Pignatti (2007) on Ukraine, by Pagés and Stampini (2009) on 3 Latin American and 3 post-transition countries ${ }^{6}$, by Bernabè and Stampini (2009) on Georgia and by Slonimczyk and Gimpelson (2015) on Russia explicitly discuss how simple transition matrices might have to be transformed to achieve comparability of the transition probabilities across

\footnotetext{
${ }^{6}$ The three transition countries are Albania, Georgia and Ukraine.
} 
states of different size. Slonimczyk and Gimpelson (2015) raise the additional issue that movements between labor market states are also determined by unobserved characteristics and that persons with different characteristics select themselves into different states. They postulate that once one takes account of the unobserved characteristics as drivers of self-selection into informal or formal employment the large difference in transition rates are attenuated or disappear.

A detailed discussion of the mobility patterns estimated in these papers can be found in Lehmann (2015). This discussion on worker mobility across the formal-informal divide leaves us with the impression that the jury is still out with respect to definitive statements about labor market segmentation in post-transition countries. The studies on Ukraine by Lehmann and Pignatti (2007) and Pagés and Stampini (2009) at any rate use very short panels. Instead, in the present paper we have data that allow us to look at medium-term transitions that help us to better understand whether workers line up in the informal sector in order to eventually enter formal salaried employment.

\section{The ULMS data, descriptive evidence and our research strategy}

\subsection{The ULMS data}

Our principal source of information is the Ukrainian Longitudinal Monitoring Survey (ULMS), a nationally representative survey of the Ukrainian work force, undertaken for the first time in the spring of 2003, when it was comprised of around 4,000 households and approximately 8,500 individuals. The second wave was administered between May and July of 2004, when sample sizes fell to 3,397 and 7,200 respectively. Data of the third wave were collected in 2007 with 3101 questionnaires of households and 6774 individual questionnaires filled out. The fourth wave in 2012 saw 3142 completed household interviews and 7122 completed individual interviews. In this paper we will only use the first three waves since we do not want to include the data point that is associated with the large shock of the Great Recession. A detailed description of the collected survey information and of the panel structure 
of the ULMS can be found in Lehmann, Muravyev and Zimmermann (2012). We, therefore, only briefly discuss here the household and individual surveys of the ULMS.

The household questionnaire contains items on the demographic structure of the household, its income and expenditure patterns together with living conditions. However, the core of the survey is the individual questionnaire, which besides generating the usual information contained in labor force surveys and information on preferences and political beliefs elicits detailed information concerning the labor market experience of Ukrainian workers. In the 2003 questionnaire, besides the reference week sections, there is an extensive retrospective part, which ascertains each individual's labor market circumstances beginning at specific points in time, namely December 1986, December 1991 and December 1997. The first two points are chosen to minimize recall bias, since the first date is close to the Chernobyl incident and the second date marks the end of the Soviet Union. The respective module is then structured in such a way that the data record the month and year of every labor market transition or change in circumstance between December 1997 and the date of interview. The surveys for 2004 and 2007 have a similar retrospective part covering the intervals 2003 to 2004 and 2004 to 2007. Since we have complete labor market histories of all those in the panel, we are able to address the issue of "roundtripping" when estimating transition probabilities between labor market states.

Since a main focus of our study is wage gap analysis it is important to provide a precise and comparable measure of earnings across the various categories of employment. ${ }^{7}$ For dependent workers we use the answer to the question about the actual net monthly wage paid ("net of taxes and without bonuses") and arrive at net hourly earnings by dividing the monthly sum by actual hours worked. Clearly, for dependent employees hourly wages are comparable for formally and informally employed workers. Self-employed workers are asked to give an estimate of their net monthly income, resulting in comparable measures of hourly earnings for formal self-employed and their informal counterparts once

\footnotetext{
${ }^{7}$ In this study we disaggregate the employment state into formal salaried employment, informal voluntary and informal involuntary salaried employment, formal self-employment and informal self-employment.
} 
we normalize by monthly actual hours worked. All hourly earnings are real, i.e., they are given in 2003 consumer prices.

\subsection{Descriptive evidence}

Before we discuss average wages and their distribution across the five employment states, we highlight interesting patterns that can be observed in tables 1 and A.1. In post-transition economies men are found to be more engaged in informal employment than women, in contrast to developing countries where females are more present in informality. From Table 1 we can infer that this higher incidence of informal employment by males is entirely due to informal self-employment, at least in Ukraine. Whilst ethnicity does not play a major role in the selection into any employment state, formally salaried workers and the formal self-employed are older than workers of the other categories and also have a higher incidence of marriage. Workers with basic elementary or less education are underrepresented in formal employment, where we find a high share of workers with higher education. It is also striking that more than three quarters of informally employed workers have vocational or secondary education; informal employment in Ukraine is hence not necessarily connected to low educational attainment and low skill levels as mooted by La Porta and Shleifer (2008) for most developing countries.

The average household size is not really different across the five employment categories. What is, however, particularly interesting is that formal salaried workers have a larger average number of other family members working in the formal sector than all types of informal workers. This fact does not seem to support the hypothesis put forth by many students of informality that workers whose other family members work in the formal sector and who are hence entitled to family-based health benefits have a predilection for informal employment. At least in Ukraine, we see households where the probability that a worker is formally employed is positively correlated with the spouse's formal employment. It is worth stressing that the thus far highlighted patterns do not differ across gender.

However, once we look at the sectoral distribution of the five employment states we find gender differences. When we look at the entire sample, formal salaried workers are predominantly employed 
in industry, education, health and social protection and public administration, informal employees whilst having an important share in industry are concentrated in agriculture, construction, and trade, hotels and restaurants; we find roughly two thirds of formal self-employed workers in this latter sector. When we splice the data by gender, we see that nearly $40 \%$ of formal male employees work in industry, while female formal employees reach a similar percentage in education, health and social protection. Table A1, which shows the distribution by sector across gender in more detail, also demonstrates large gender differences with respect to self-employment. Among informal self-employed females more than half work in agriculture while this share among their male counterparts is less than one third. One the other hand, more than a third of male self-employed informal workers is engaged in construction, while the percentage for females in this sector is unsurprisingly very small. When it comes to informal selfemployed in trade, hotels and restaurants we find substantial and not too different percentages for both sexes. When we look at formal self-employment, females have a whopping $81 \%$ share in this sector whilst for males this share amounts to slightly more than one half. Large gender differences in the employment shares are also given regarding both voluntary and involuntary dependent informal employees. Male workers in these employment categories have large shares in construction, whilst shares for their female counterparts are miniscule. On the other hand, nearly two thirds of female dependent informal employees work in trade, hotels and restaurants irrespective of whether they are there of their free will or not. In contrast, male workers in these employment categories have a much smaller share.

Turning to the distributions by firm size shown in table 1 we find that in the new century formal employees work in their majority still in large firms. What is also striking is the large share of informal employees in relatively large firms. Since it is unlikely that firms of this size are in the informal sector, we deal here with many informal employment relationships within the formal sector. Unsurprisingly, self-employed workers, whether formal or informal, work predominantly in micro firms. ${ }^{8}$ Finally, from

\footnotetext{
${ }^{8}$ It is certainly surprising that $2 \%$ of the self-employed report to work in environments where there are more than one thousand employees. However, the results shown are responses to the following question: "What is the total number of people working at this enterprise/organization/workplace for self-employed?" and do not represent the
} 
the distribution of shares across macro-regions it is difficult to answer the question whether informal employment is a regional issue in Ukraine.

Table 2 provides multinomial logit estimates of employment states in the form of odds ratios for the entire sample. These estimates confirm the previous interpretation of our descriptive statistics or give us a clearer view where descriptive statistics are not revealing. There is confirmation that women are strongly underrepresented in informal self-employment, that voluntary informal salaried workers are younger and that older workers are particularly engaged in formal self-employment. We also find confirmed that formal employees live in households with other formal salaried workers and that workers with higher educational education work disproportionately as formal salaried employees or formal selfemployed.

Regarding the sectoral structure of employment types we establish strong evidence that informal self-employment is concentrated in agriculture and that voluntary and involuntary informal employees as well as the formal self-employed work predominantly in construction, as well as trade, hotels and restaurants. In contrast, formal employees dominate in industry, education, health and social protection as well as public administration. We also see that informal employment relationships are predominantly in small firms and that this is especially the case when it comes to any form of self-employment. The regional patterns of employment types do not become much clearer with the MNL estimates. In an online appendix we also present MNL estimates separately for women and men. ${ }^{9}$ These estimates do not diverge much from those for the entire sample. It is worth stressing, though, that the large and highly significant odds ratios for voluntary and informal employees in construction are entirely driven by men and that self-employed informal male workers are of great importance in construction while all the odds ratios for women in this sector are insignificant. In contrast, both female and male involuntary informal employees and formal self-employed are disproportionately represented in trade, hotels and restaurants.

number of workers hired by the self-employed. Those self-employed who hire workers have two employees on average.

${ }^{9}$ The online appendix can be found on the IZA website at the link: http://ftp.iza.org/dp11256_app.pdf. 
Table A1 tells us that about half of all informal self-employed females work in agriculture, while about a third of males of this employment state work in the sector. Since we consider these workers subsistence farmers we exclude them from the further analysis for reasons we discuss in the research strategy section.

Figure 1 shows the evolution of the distributions of real hourly earnings of all workers over the panel period, while Figures 2-4 present the earnings distributions for the five employment categories in 2003, 2004 and 2007. We see a substantial rightward shift of the earnings distributions between 2003 and 2007 in Figure 1, an indication of strong real wage growth in the analyzed period. The first row in table 1 reports the mean real hourly earnings in Hryvnia averaged over the three years for the entire sample and by gender. Self-employed workers, whether formal or informal, have far higher mean earnings than salaried employees. Among the latter types of workers involuntary informal workers have the lowest average earnings whilst their voluntary counterparts have slightly higher average earnings than formal employees. We also see a gender wage gap across all employment categories. The large standard deviations relative to the estimated mean earnings point to the tremendous heterogeneity of individual earnings within employment categories, where this heterogeneity is particularly pronounced among the formal and informal self-employed.

The distributions of real earnings across the five employment types, shown in Figures 2-4 for the entire sample, confirm this heterogeneity and provide us with additional interesting information. Since the earnings distributions of the five employment categories have similar relative profiles across the three years we restrict the discussion to the profiles for 2003. As reflected in the standard deviations given in Table 1, formal and informal salaried workers are confronted with substantially more compressed earnings distributions than the formal and informal self-employed. What is striking is that the distribution of the formal self-employed has a lot of mass to the right of the distribution of formal salaried workers but hardly any mass to the left and lower part of the formal salaried distribution. So, there are many formal self-employed who earn high wages. In contrast, as far as the informal selfemployed are concerned, there is some small mass to the right and upper part of the distribution of 
formal salaried workers, and a lot of mass to the left and lower part of the formal salaried distribution. Hence there are many informal self-employed who earn very low wages and only a few with high earnings. Among salaried workers, those who are involuntarily informal are confronted with the lowest wages throughout as inspection of Figure 2 demonstrates: there is a very large chunk of the distribution to the left of the formal salaried distribution and at higher wages the distribution is to the left of the formal salaried distribution throughout. So, on this evidence involuntarily informal salaried workers seem to do worse than formal salaried workers and all the other employment groups. The voluntarily informal salaried workers, on the other hand, are confronted with a somewhat wider distribution than the formal salaried, with quite a few workers earning higher wages and only a few that have worse earnings.

The earnings distributions presented separately for women and men in the online appendix point to some interesting gender differences. Women and men have similar real wage growth between 2003 and 2007 as figures B1 and B2 attest. The larger average earnings for men shown in table 1 are also confirmed for overall earnings in all three years. Turning to the earnings distributions across the five employment types allows us to refine the analysis of the relative wage positions across employment status that we discussed in the previous paragraph. We again focus on the year 2003 since the relative earnings profiles are similar across years for each gender as inspection of figures B3 - B8 reveals.

Male formal salaried workers have a wider earnings distribution than females in this employment group. The male distribution is also located more to the right than the one for females. Inspection of figures B3 and B4 also allows us to infer that there are a lot more formal salaried women who earn very low wages than men while we observe the opposite in the high wage segment. The gender differences for the formally self-employed are also striking. In the very low part of the earnings distribution we find more female formal self-employed than dependent formal employees, implying that a relative large share of female formal self-employed earn very low wages. In contrast, hardly any of the male formal self-employed earns truly low wages. When we compare the upper tails for this employment group across gender we also can infer that it is particularly men who in great numbers earn high wages, while 
there are less female formal self-employed who earn such wages. These relative gender differences with the formal self-employed might be related to the higher share of males in other services, which include transportation, financial and real estate services, while females are predominantly in trade, hotels and restaurants where average earnings are lower. ${ }^{10}$

When it comes to informal self-employment we see relatively similar patterns across gender: relative to formal salaried workers there are a lot of informal self-employed with very low earnings, and only few with high earnings. However, we do see a fatter tail in the upper part of the male distribution, which might explain the relatively high average earnings. Males who are involuntary informal dependent employees seem to be especially penalized with respect to earnings as there are many such workers in the lower earnings segment and hardly any in the upper segment. For women of this employment type penalties seem more attenuated across the distribution. The situation is reversed as far as voluntary dependent informal employment is concerned as women seem more penalized than men relative to formal salaried workers.

The presented descriptive evidence on the earnings distributions leads us to conclude that it is crucial to undertake the analysis of the formal-informal earnings gap across the whole distribution and to divide the data by gender. Only in this way will we produce the refined picture of the labor market in Ukraine that is necessary to properly discuss labor market segmentation.

\subsection{Our research strategy}

To test for labor market segmentation we pursue two approaches, the analysis of worker mobility across labor market states and wage gap regressions at the mean and across the entire earnings distribution. Regarding the analysis of worker mobility we use a panel across a longer interval than done thus far in

\footnotetext{
${ }^{10}$ Average hourly earnings of the formal self-employed in trade, hotels and restaurants are 4.59 Hryvnia, while they are 5.22 Hryvnia in other services.
} 
the literature on post-transition countries. We also take advantage of recent advances in fixed effects quantile regression that allow us to produce consistent estimates even with a relatively short panel.

Regarding our transition estimates, our analytical approach follows Clark and Summers (1979) and Bellmann, Estrin, Lehmann and Wadsworth (1995) in assuming that transitions between labor market states are governed by a Markov process. This implies that the transition is only a function of the previous state. Having the states of formal salaried employment (FS), voluntary informal salaried employment (VI), involuntary informal salaried employment (INVI), formal self-employment (SEF), informal self-employment (SEI), unemployment (U) and inactivity (OLF), we have 49 potential transitions, where the gross probability of transition from state $\mathrm{i}$ to state $\mathrm{j}$ can be written as:

$$
P_{i j}=\frac{F_{i j}}{S_{i}}, \quad i, j=F S, V I, I N V I, S E F, S E I, U N, O L F
$$

where $F_{i j}$ is the number of persons flowing from state $\mathrm{i}$ in period $\mathrm{t}-1$ to state $\mathrm{j}$ in period $\mathrm{t}$ and $S_{i}$ is the number of persons in the origin stock in period $t-1$. Finally, under Markovian assumptions duration of state occupancy is exponentially distributed and given by the reciprocal of the outflow rate:

$$
\frac{1}{\sum_{j} P_{i j}}, j \neq i .
$$

In our analysis we rely on two intervals of transitions, 2003 to 2004 and 2003 to 2007. Comparing the transitions of the short-term matrix with the transitions of the medium-term matrix we attempt to answer the following questions: what are the preferred employment states of Ukrainian workers, that is in which states do we find particularly long average durations of state occupancy? Are Ukrainian workers lining up in informal employment to eventually enter formal salaried employment? Do the informal self-employed show different transition patterns from informal salaried workers? To see whether there is heterogeneity in transitions across gender and age, we estimate short- and mediumterm transition probability matrices for the entire sample, for women and men, and for three age groups. 
Our focus on the transitions and the relative durations of state occupancy in the medium-term for the seven labor market states allows us to get credible answers to these questions without transforming the $\mathrm{P}_{\mathrm{i}, \mathrm{j}}$ matrices in any way. We also do not need to construct counterfactual matrices that capture no segmentation and compare these to the actual transition probability matrices as is done, for example, in Pages and Stampini (2009). The construction of these counterfactual matrices requires several assumptions that cannot really be verified with the two-year panel that the authors have at their disposal.

Estimated transition probabilities might be affected by the problem of "round-tripping", i.e., when persons appear in the same state at time $\mathrm{t}$ and $\mathrm{t}-1$ but have changed their status between the two points in time. "Round-tripping" might be a particularly serious problem for medium-term transitions. In what follows we, therefore, present transition probability estimates with and without "roundtrippers." Since we have a complete labor market history of each individual in the panel we can establish whether this person changed state between times $t$ and $t-1$. We should point out, though, that the relative magnitudes are similar whether we have excluded "round-trippers" or not. A second issue that might bias our transition estimates is selection due to attrition. Simple probit regressions demonstrate that workers in informal employment relationships are slightly more likely to attrite than workers who are formal. ${ }^{11}$ We do not believe, however, that the very strong results obtained are due to attrition. ${ }^{12}$

We assume that the informal self-employed in agriculture are subsistence farmers. It is highly unlikely that these farmers will ever change their employment status. Retaining these individuals in the sample would, therefore, bias our results in that we would have a longer average duration of state occupancy than when we eliminate these individuals from the analysis. In other words, the employment status informal self-employment would appear more desirable than it actually is for those who can

\footnotetext{
11 These probit regressions are available upon request.

${ }^{12}$ In the wage gap analysis we provide a robustness check where we explicitly control for potential selection bias due to attrition.
} 
and/or are willing to move between states. ${ }^{13}$ Therefore, it strikes us as sensible to eliminate the informal self-employed in agriculture from the analysis.

Our second approach of testing the nature of the Ukrainian labor market relies on wage gap analysis estimating various types of Mincer equations. To estimate formal-informal wage gaps at the mean, we use pooled OLS regressions, pooled Heckit regressions to account for self-selection into employment as well as fixed effects regressions taking advantage of the three waves of the ULMS. In all our earnings regressions we control for gender, ethnicity, age, educational attainment, tenure, firm size and part-time work as well as for back pay, wage arrears, occupation, sector and ownership of the firm. We also add dummies for the three informal types of employment and for formal self-employment; so, we estimate wage gaps relative to formal salaried workers. The exclusion restrictions for the Heckit models are household size, number of dependent children, number of other formal salaried members in the household as these variables predict participation but not earnings. The fixed effects regressions control for time-invariant unobserved heterogeneity.

To test for selection due to attrition and incidental truncation in fixed effects regressions we follow Wooldridge (2002). As far as attrition is concerned we add a lead selection indicator term $\mathrm{s}_{\mathrm{i}, \mathrm{t}+1}$, which always takes the value 0 if the individual i remains in the sample throughout the panel, and the value 1 just prior to dropping out of the sample. Since we have $T>2$ with our ULMS panel we can perform this test of the effect of attrition on the response variable earnings. To test for the impact of selection due to incidental truncation we follow Wooldridge (1995) and estimate a general participation equation in the presence of unobserved time-invariant heterogeneity, with the resulting lambda $(\lambda)$ added into the fixed effects earnings regressions. We perform our selection tests by including $\mathrm{s}_{\mathrm{i}, \mathrm{t}+1}$ and $\lambda$ separately and jointly into the regressions.

\footnotetext{
13 In actual fact, when we include the informal self-employed in agriculture the diagonal element for informal selfemployment in the $2003-2007$ transition probability matrix is 0.44 , whilst it is only 0.18 when we exclude these individuals.
} 
The second leg of our wage gap analysis consists in pooled quantile and fixed effects quantile regressions. Clearly, estimating the wage gap for different types of informal employment and selfemployment across the entire distribution is more illuminating than just estimates at the mean. For example, informal self-employed workers might incur a wage penalty in the lower part of the distribution and a wage premium at high deciles, pointing to segmentation within the self-employment part of the informal sector (Tokman 1986 and Fields 1990). Selection problems are also relevant with quantile regression, of course. Until recently, having a short panel made it nearly impossible to properly correct for selection biases using a fixed effects model. However, the quantile regression estimator for panel data (QRPD) with non-additive fixed effects developed by Powell (2016) is consistent even if T is small. Hence, having a very short panel with $\mathrm{T}=3$ is no longer an impediment when estimating informal-formal earnings gaps across the entire distribution consistently, i.e., when correcting for timeinvariant heterogeneity throughout the distribution. ${ }^{14}$

\section{Main results}

\subsection{Mobility analysis}

Tables 3 and 4 show annual transition probabilities and transition probabilities spanning four years respectively, with panels A presenting the probabilities when "round-trippers" are included, while panels B show the results without "round-trippers". The exclusion of "round-trippers" produces a loss of 200 observations with the short-term transitions matrix, while we lose 662 observations in the case of the medium-term transitions matrix. However, inspection of the entries in panels A and B does not demonstrate major differences as far as the relative magnitudes of transition probabilities are concerned. Since the cleaner versions of transition probabilities are given without "round-trippers", we concentrate on panels B of Tables 3 and 4 in our discussion.

\footnotetext{
${ }^{14}$ Concretely, we employ the Stata package "qregpd" when estimating wage gaps for the three types of informal employment and for the formal self-employed.
} 
The entries denoted $P_{i \text {. }}$ represent the share of the given group at the beginning of the period, the entries denoted $P_{. j}$ at the end of the period. In the 2003-2004 matrix we can see a slight rise of the share of formal salaried workers from $48 \%$ to $49 \%$, while this rise is with 6 percentage points more pronounced between 2003 and 2007. Hence we see a strong growth of formal salaried employment in our sample. It is also striking that all types of informal employment increase their shares between 2003 and 2007, whilst both unemployment and inactivity see falling shares. This fall is partially absorbed by the increase in formal salaried employment, and partially by a strong rise in all types of informal employment. Formal self-employment sees a doubling of its share in the medium-term, pointing to increased opportunities for the formally self-employed as the growth of the Ukrainian economy became more robust in the first decade of the new century.

The diagonal entries in the matrices are particularly revealing with respect to the desirability or stability of a state. In states where the $P_{i j}(\mathrm{i}=\mathrm{j})$ entries are large state occupancy is long, i.e., workers entering such states prefer to remain in them, whilst states with $P_{i j}(\mathrm{i}=\mathrm{j})$ relatively small exhibit a short state occupancy, i.e., workers entering such states prefer to leave them or are forced to leave them. In the period 2003 to 2004, stable states are on this measure any type of formal employment, and inactivity. On the other hand, any form of informal employment as well as unemployment are volatile or undesirable states. When we look at the medium-term matrix of Table 4, this dichotomous nature of labor market states is even more apparent. While the stable states still exhibit very large shares of stayers, the volatile states have tiny shares or a zero share of stayers. Of course, it is well known that unemployment state occupancy cannot be large over a four year period of growth. What is interesting for us here is, however, the fact that on our measure informal salaried employment, whether voluntary or involuntary, is essentially an undesired state. Informal self-employment, on the other hand, seems to some minor degree a desirable state since roughly one fifth of those in this state in 2003 still find themselves in it in 2007. Overall, though, the diagonal entries carry the clear message that formal dependent employment and formal self-employment are the two stable and desirable states in the Ukrainian labor market. 
The transition probabilities from the seven origin states to the seven destination states can shed additional light on the desirability of employment states. Even a cursory inspection of panels B in Tables 3 and 4 makes it clear that the flows in the short interval are similar in their structure to the flows of the medium-term period. Since the flows in the latter period are particularly pronounced, we focus here on the medium-term transition probabilities.

Most workers who were formal dependent employees retain their status; there are some flows into informal salaried employment and into formal and informal self-employment. However, the largest shares of flows out of formal dependent employment have the destination states unemployment and inactivity. The relative size of these transitions is not very surprising, but it does make the point that transitions from formal into informal dependent employment are very marginal. Looking at the voluntary informal salaried employed, we find that nearly half of the workers being in this state in 2003 have secured a job as a formal salaried worker. Roughly a quarter find themselves involuntarily in an informal job, and $13 \%$ have become formal self-employed. So, more than $60 \%$ of voluntary informal salaried workers have successfully queued in their origin state in order to enter formal employment. Those workers who in 2003 were involuntarily in informal salaried employment have also accessed a formal salaried job in large numbers in 2007. The second most important destination for this group of workers is informal self-employment. It seems plausible from the shown transition probabilities that formal salaried workers leave their state predominantly choosing unemployment or inactivity, while in their majority informal salaried workers use their states as a waiting stage to enter formal salaried employment if at all possible. Those who are not successful in doing this end up mostly as involuntary informal salaried workers (in the case of the originally voluntary informal employees) or in informal self-employment (in the case of the originally involuntary informal employees).

The transition flows of the self-employed are rather different. In the case of formal selfemployment only a minority of workers moves out of the state; those who move out have formal salaried employment as their main destination state. As far as informal self-employment is concerned, more than a third of workers originally in this state become formal employees, while $12 \%$ switch from informal 
to formal self-employment. From these flows we can draw the inference that is desirable to distinguish between dependent and self-employed informal workers: a substantial fraction of the informal selfemployed prefer to remain in their state, while informal dependent employees exit their state when they can. It is also worthy to stress that by far the most desirable destination state for movers is formal salaried employment.

We also briefly comment on the flows of one of the two other labor market states, unemployment. The two largest destination states are formal salaried employment and inactivity: more than two thirds of unemployed workers find a formal job or become discouraged and leave the labor market. We also see relative large shares for the destination states involuntary informal dependent employment and informal self-employment.

Tables A2 - A5 in the appendix and Tables B3 - B8 in the online appendix present transition probability matrices for the same short-term and medium-term periods with the sample split by gender and into three age groups respectively. The transition flows of women and men are very similar and in line with the flows of the entire sample. Only as far as informal self-employment and involuntary dependent informal employment are concerned do we observe some differences between the sexes. Women tend to remain in informal self-employment at more than double the rate of men and enter formal salaried at roughly half the rate as men do. On the other hand, men leave informal selfemployment in larger numbers than involuntary dependent informal employment. Hence, at least as far as men are concerned all types of informal employment seem equally undesirable.

Turning to the medium-term transitions by age group (tables B6-B8) we see that for all groups formal dependent employment and formal self-employment are the stable and desirables states and by far the largest destination for workers coming from informal employment is formal salaried employment. There are, however, some differences across the three age groups. Young workers (age 15 - 29) have a relative low share of stayers in formal self-employment and no one remains in informal self-employment after the 4 years. A comparison of table 4 with tables B7 and B8 demonstrates that 
workers in the core group (age $30-44$ ) and older workers (age 45 - 59) have very similar flows patterns to those of the overall sample.

Table A6 in the appendix demonstrates that roughly half of employment status switchers status also change sector and that this fraction does not differ significantly by gender. However, we can also see that for workers whose origin state was formal salaried employment this fraction is higher while for workers with origin state voluntary informal dependent employment this fraction is substantially smaller than $50 \%$. In addition, female workers with origin state informal self-employment have a ratio that is with $33 \%$ particularly low. We perform a robustness check in the wage analysis below by including a dummy for those workers who both changed employment status and sector since Lehmann, Pignatti and Wadsworth (2006) find wage penalties for re-employed displaced workers who switched sector in the Ukrainian labor market.

\subsection{Wage gap regressions}

\subsubsection{Wage gap regressions at the mean}

Table 5 presents the results of three models: pooled OLS, pooled Heckit and a fixed effects (FE) regression model. The first 3 columns give the results for the whole sample, while columns 4 to 6 contain the estimates for women and columns 7 to 9 for men. Estimates of the selection equations for the entire sample and by gender can be found in table B9 in the online appendix. Average household size, number of other family members in the formal sector and number of dependent children are the exclusion restrictions underlying the pooled Heckit regressions: they are significant in the selection equations but have no predictive power in the wage regressions. Unsurprisingly, average household size lowers female participation, and the number of dependent children reduces participation by women but increases it for men. It is also striking that a larger number of other household members working in the formal sector increases labor force participation of both sexes. 
The results of table 5 show reasonable parameter estimates on the demographic variables that are very similar for the pooled OLS and the Heckit specifications. ${ }^{15}$ For example, women incur a wage penalty of about $22 \%$, Ukrainian workers a small penalty of around $4 \%$, which is in line with the work of Constant, Kahanec and Zimmermann (2012). In our results, this penalty is concentrated on female workers. Workers with higher educational attainment, on the other hand, have a large premium ranging between a whopping $39 \%$ to a modest $13 \%$ in the male FE specification.

The parameter estimates that mainly interest us are related to the dummies for the three types of informal employment and for formal self-employment. They reflect a mean wage premium or wage penalty relative to formal salaried workers. Before we discuss the various parameter estimates we need to touch upon potential biases introduced in the FE regression because the effects are identified by those who move in and out of a state. Descriptive statistics on the characteristics of "stayers" and "movers" related to an employment state do not show significant differences. ${ }^{16}$ Furthermore the differences in the estimates on the employment dummies are not statistically significant as inspection of Table 5 makes clear. This leads us to believe that the FE estimates are not driven by the peculiar nature of "movers" and that the estimates control for unobserved heterogeneity regarding the full samples and not the samples of movers.

At the mean, voluntary informal employees receive a wage premium of between about $16 \%$ in the Heckit specification to $22 \%$ in the FE specification when we look at the whole sample. When we split the sample by gender we get similar coefficients in the OLS and Heckit specifications, while the wage premia in the fixed effects case are no longer significant. Especially interesting is the category of involuntary informal salaried workers, who make up the majority of informal employees. Looking at the whole sample, they incur a wage penalty of roughly $7 \%$ in the pooled OLS and Heckit specifications.

\footnotetext{
${ }^{15}$ Heckman's lambda is never significant in our estimations, implying that selection into employment does not affect the results. This can also be seen by the fact that the parameter estimates of the pooled OLS and of the Heckit models are very close.

${ }^{16}$ These descriptive statistics are not shown here, but available upon request. We should add the caveat here that a comparison of "stayers" and "movers" is not operational for the two states of dependent informal employment since we have seen in the mobility analysis that in the end all workers originating from these two states have eventually left these states.
} 
This wage penalty disappears when we control for time-invariant unobserved characteristics in the FE regression. Hence, those involuntarily employed in informal jobs seem to have worse unobserved characteristics than formal salaried workers. Formal self-employed workers receive large wage premia between $34 \%$ and $67 \%$ whether we look at the entire sample or women and men separately. These premia are not eliminated once we control for unobserved time-invariant characteristics. The joint sample of female and male informal self-employed also have wage premia that are large and that do not disappear when we control for time-invariant unobserved characteristics. So, selection problems seem to play a minor role in the Ukrainian labor market in contrast to the evidence on other developing countries presented, e.g., in Bargain and Kwenda (2011, 2014): essentially wage premia for the formal and informal self-employed at the mean do not disappear once we control for time-invariant unobserved characteristics of the workers involved.

Our first robustness check consists in re-estimating the 3 models with the informal selfemployed in agriculture included (see table B10 in the online appendix). A comparison of tables 5 and B10 shows no substantive differences in the estimated coefficients on the employment status dummies. A second robustness check concerns the selection problem due to attrition and incidental truncation when we estimate the FE model. Following Wooldridge (2002) we have added an attrition term or a Heckman selection term or both to our FE regressions. The results of these regressions are presented in table B11 of the online appendix. We should make two observations with respect to this table. First, comparing Table 5 and Table B11, the coefficients on all the variables in all specifications of the FE model do not substantially change when we test for selection bias due to attrition or incidental truncation. Second, neither the coefficient on the attrition term nor on lambda is statistically significant whether we introduce the attrition dummy and lambda separately or jointly. Consequently, selection bias due to attrition or incidental truncation seems to be a very minor problem if any in our FE regressions. In the pooled OLS and Heckit regressions we also add a dummy for those who switched employment status and sector. The coefficients on this dummy are close to zero and never statistically 
significant, hence switching both employment status and sector does not entail a wage penalty with our samples. ${ }^{17}$

The upshot of our results regarding wage gaps at the mean is that voluntary informal salaried workers, the formal and informal self-employed receive wage premia that do not disappear once we control for unobserved time-invariant workers' characteristics. In contrast, workers who are involuntarily informal employees experience a wage penalty that disappears once we control for unobserved heterogeneity, implying that workers with unobserved unfavorable characteristics find themselves in this state. These two conclusions are above all valid when we inspect the results for the entire sample, while the results for women and men separately are less strong due to reduced sample size. It is, therefore, important to buttress these conclusions with wage gap analysis across the entire earnings distribution.

\subsubsection{Quantile wage gap regressions}

We present the coefficients of the four employment states at the quantiles for pooled quantile wage regressions in Table 6 and for fixed effects quantile wage regressions in table 7, where we control for unobserved time-invariant characteristics of respondents. The coefficients estimates should be understood as returns relative to the returns of formal salaried workers at the respective quantile. These estimates are presented for the entire sample (upper panel), for women (middle panel) and for men (bottom panel). The regressions on which tables 6 and 7 are based are shown in extended form in tables B12-B17 in the online appendix.

We first discuss the estimates on all the variables apart from the employment types in Table B12, i.e., when we do not control for time-invariant unobserved heterogeneity. We then confront these estimates with those coming out of the fixed effects quantile regressions in B15. ${ }^{18}$ Finally, we turn to our main

\footnotetext{
17 The results of this last robustness check are not shown here, but available upon request.

${ }^{18}$ The results for women and men in tables $13-14$ and $16-17$ are grosso modo similar to the results gotten with the entire sample. To save space we do not discuss these tables here and leave it to the reader to explore these tables.
} 
focus, the returns of four employment types relative to the returns of formal employees, comparing the results of the pooled and of the fixed effects quantile regressions in tables 6 and 7 .

In Table B12, the gender wage gap is quite pronounced and increasing with higher hourly earnings; also, workers of Ukrainian ethnicity have a small wage penalty throughout the distribution. One additional year of tenure gives a slightly higher return at all percentiles, while age, on the other hand, plays a role only at the $3^{\text {rd }}$ decile and in the upper part of the distribution, producing a small premium for older workers. As far as educational attainment is concerned it is only higher education that gives higher and increasing returns relative to basic elementary and less education as we sweep through the distribution. Part-time workers experience a small wage penalty in the bottom decile but large and monotonically increasing premia from the fourth decile onwards. From the second decile to the median, married workers get a slightly higher wage than workers who have another civil status. When we control for time-invariant unobserved heterogeneity in Table B15, we see similar effects across the distribution as in Table B12 for higher education, tenure, part-time and married workers. Age, on the other hand, has a positive impact only at the seventh decile, but negative profiles nearly everywhere else in the distribution. Also, vocational and secondary education now generate positive returns between the second decile and the median, negative and positive returns at the eight and the ninth deciles respectively.

The estimated coefficients on the employment type dummies presented in tables 6 and 7 are, of course, the main focus of our analysis here. We report sequentially on each employment state, for the entire sample, by gender, and without and with fixed effects. Voluntary informal employees have a wage premium only in the upper part of the distribution as long as we do not control for time-invariant unobserved heterogeneity. Splitting the data by gender, we see that this premium falls predominantly on women. When we introduce fixed effects, relative returns increase nearly throughout the distribution. One needs to carefully interpret this finding. Since we compare the earnings of workers in the informal state to the earnings of formal salaried workers an increase in relative returns once we control for timeinvariant unobservable characteristics can be explained by negative selection of the informally 
employed and/or positive selection of the formal employees. In other words, the voluntary informal employees have unobservable characteristics that lower their earnings in their informal jobs while the formal employees have unobservable features that are particularly beneficial in their held jobs. In the fixed effects regression this negative effect related to the informal employees and/or this positive effect related to formal employees are eliminated and the relative returns increase. We cannot disentangle these two effects and also cannot establish whether only one effect or both effects are in play and when both effects are present which effect prevails. But, as long as the earnings gap becomes larger as we go from pooled regression to fixed effects regression we can speak of negative selection of the voluntary informal employees.

Involuntary informal employees are confronted with wage penalties, above all in the lower part of the distribution when we do not control for unobserved characteristics. These wage penalties are quite similar across gender. When we include fixed effects these penalties disappear in some deciles, implying that negative selection for involuntary informal employees is an issue in the Ukrainian labor market. However, since wage gaps are not everywhere eliminated with the introduction of fixed effects at most deciles, segmentation is prevalent for the majority of involuntary informal employees.

The formal self-employed do especially well relative to formal employees as they have wage premia throughout the distribution that are monotonically rising to a whopping 83 percent in the highest decile. When we do not control for unobserved characteristics, self-employed women have particularly high relative returns. For both women and men we see an increase in relative returns once fixed effects are included. Also in this case, the results point to some degree of negative selection: the self-employed seem to have time-invariant unobserved characteristics that lower their earnings in self-employment or their formal salaried counterparts have some unobservable characteristics that make them particularly suitable for formal salaried employment. At any rate, introducing fixed effects raises relative earnings for the formal self-employed. 
The informal self-employed also do exceptionally well but only from the second decile onward, with a return in the highest decile that is 68 percent higher than formal employees. The relative returns that are significant above all in the upper part of the distribution are particularly large for women. Once fixed effects are added we see wage premia throughout the distribution for the entire sample and for women, while men get wage premia from the second decile onwards. It is striking that men throughout the distribution and women in its lower part get increasing relative returns once we account for unobserved characteristics, again pointing to some degree of negative selection. However, in the upper part of the distribution female informal self-employed experience a reduction in their relative returns. So, there is some positive selection in the case of these women; they have time-invariant unobserved characteristics that make them especially suitable for informal self-emplyoment, hence pushing down the wage premia estimates in the fixed effects quantile regressions.

The main point of our quantile regression results, however, is that while involuntary informal employees are confronted with wage penalties, workers in the other employment categories experience large wage premia either throughout the distribution (the formal and informal self-employed) or through large parts of the distribution (the voluntary informal employees). For the most part, these penalties or premia, while often altered in size, are not eliminated once we control for time-invariant unobserved characteristics.

\section{Discussion and conclusions}

By combining the accumulated evidence regarding transitions between labor market states and wage gaps at the mean and across the earnings distribution we are able to shed some new light on the issue of labor market segmentation in Ukraine. By eliminating the informal self-employed in agriculture we produce evidence that can be better linked to the various schools of thought regarding the role of informal employment in the labor market. Slicing the data by gender and age groups helps us in addition to draw a refined picture of labor market patterns in Ukraine along the formal-informal divide. 
The medium-term transitions presented in panel $\mathrm{B}$ of Table 4 give us the clear message that formal salaried employment and formal self-employment are especially desirable employment states since the estimated duration of state occupancy is very long. When considering the measure of duration of state occupancy, the least desirable states are informal dependent employment. What is striking in this context it the fact that also workers who are voluntarily in this state do not want to stay in it in the medium-term. As far as voluntary and involuntary dependent employees are concerned, the transition probabilities indicate that both categories use informal employment as a waiting stage to get into other types of employment relationships, foremost formal salaried employment. Those among the voluntary informal employees who are not able to end up in formal dependent employment or in formal selfemployment, remain informal employees but now against their volition, hinting at some adverse selection for a minority of these workers. The originally involuntary informal employees finish in informal self-employment if they cannot enter formal salaried employment. In consequence, on this evidence the labor market seems certainly segmented for dependent employees: as found by Pagès and Stampini (2009) for Ukraine and Bernabè and Stampini (2009) for Georgia, workers line up in the informal state to enter eventually formal employment.

The second important message from the transitions analysis concerns the nature of informal selfemployment in the Ukrainian labor market. Clearly, for a large number of the informally self-employed this state like dependent informal employment is undesirable, since when we look at the entire sample only $18 \%$ remain in this state and more than a third find jobs in formal salaried employment. There is, however, a substantial number of workers, amounting to $25 \%$ in the case of women, who like to remain in this state. The dichotomous nature of informal employment between dependent informal employment and informal self-emploment, found by Perry et al. (2007) for Latin America and by Maloney (1999, 2004) for Mexico seems to be less important in the Ukrainian labor market. Since nearly half of the informal self-employed enter formal salaried employment or formal self-employment we can moot that for a majority of workers in informal self-employment this employment type seems to be a state of last 
resort that is prefered to unemployment, given the very ungenerous unemployment benefit system (Earle and Sakova 2000). ${ }^{19}$

The results of the wage gap analysis at the mean in Table 5 seem to point to an integrated Ukrainian labor market as far as dependent informal employees are concerned. Voluntary informal employees have a return that is 22 percentage points higher than their formal counterparts even when we control for unobserved heterogeneity. Those who are involuntarily informal employees have a substantial wage penalty that disappears once we control for time-invariant characteristics of these workers. So, the reason that we observe a wage penalty at the mean is because these workers have relative to formal salaried workers worse unobserved traits. Once we control for them the penalty disappears. As we have seen with the medium-term transition probability estimates for the formal selfemployed they like to be in this state. The wage gap estimates at the mean are in line with this scenario since the formal self-employed have a substantial mean wage premium that is only slightly lowered in the fixed effects regressions. When it comes to the informal self-employed we get some ambivalent results. On the one hand, the medium-term transition probabilities demonstrate that the informal selfemployed leave this state and enter formal employment in large numbers. On the other hand, we see a wage premium at the mean that does not disappear once we add fixed effects. ${ }^{20}$

The results of the quantile regressions give a rather complex picture regarding the segmentation issue. When we look at the results for the involuntary informal employees we see wage penalties in the first seven deciles when unobserved heterogeneity is not controlled for (Table 6). Once we control for it, wage penalties exist from the first to the eight decile, with the penalties turning, however, insignificant at some deciles, including the the median and the ninth decile. The fact, however, remains

\footnotetext{
19 The relative transition patterns are quite similar whether we look at the entire sample or women and men or age groups separately. However, there are some differences. For example, women tend to stay more in informal self-employment, and young workers whose origin state is informal employment and who are unable to enter formal salaried employment enter unemployment, while older workers who are in the same situation leave the labor force. This latter difference in destination states is, of course, reasonable given the different age groups.

${ }^{20}$ The fixed effects point estimates of the wage premia when splitting the data by gender, whilst statistically insignificant, are similar to the estimate with the entire sample. Hence, we think that this result is rather due to sample size than to positive selection - recall that a reduction in a wage premium once fixed effects are introduced is due to positive selection
} 
that even when unobserved time-invariant characteristics are taken into account involuntary informal employees get lower earnings than their formal counterparts in most of the distribution. The voluntary informal employees, when controlling for unobserved heterogeneity experience wage premia nearly throughout the distribution. We establish this scenario also when we estimate fixed effects regressions separately for women and men. Finally, both the formal and informal self-employed experience large wage premia throughout the distribution. Again, these results are confirmed in the quantile regressions that are estimated separately for women and men.

As far as involuntary informal employees are concerned, both the mobility analysis and the wage gap analysis produce evidence of a segmented labor market. These workers in their majority line up in informal employment to eventually enter into formal salaried employment and most of them are confronted with wage penalties. For the formal self-employed the results are also clear-cut: in their majority, these workers like their employment state and they receive large earnings premia throughout the distribution. A puzzle arises when we confront the results of the mobility analysis with those of the wage gap analysis for voluntary informal employees and the informal self-employed. Both types of workers line up in informal employment with the clear intention to enter either formal dependent or formal self-employment if at all possible, while they do receive large wage premia throughout or through most of the distribution. Hence, they do not like to remain in their given state even though their remuneration is substantially higher than if they were formal employees. One explanation of this seeming contradiction could be that workers in Ukraine value the security of a formal job very highly independent of the wages they earn. Tables A7 and A8 provide some descriptive evidence that seems to buttress this judgement. Workers in both types of formal employment have the highest job satisfaction and life satisfaction scores. On the other hand, involuntary informal employees and the informal selfemployed have far lower scores.

So, is there segmentation in the Ukrainian labor market in the years 2003 to 2007? The answer seems an unequivocal yes for involuntary informal employees who make up the majority of dependent informal workers. These workers line up for formal employment in the medium term and many of them 
experience wage penalties even when time-invariant unobserved characteristics are controlled for. For voluntary informal employees and the informal self-employed we get a more complex picture. While both types of workers also predominantly enter formal salaried employment over a four year period most of them receive large wage premia. So, on one measure we find segmentation along the formalinformal dimension, while on the measure of the wage gap segmentation is not confirmed. More research is certainly needed to address this apparent contradiction. On the other hand, we might surmise that the experiences of workers in post-transition countries like Ukraine are far too heterogenous and complex to render them easily elements of a pre-conceived taxonomy. 


\section{References}

Bargain, O. and Kwenda, P. 2011. Earnings structures, informal employment, and self-employment: New evidence from Brazil, Mexico and South Africa. Review of Income and Wealth 57: S100 $-\mathrm{S} 122$.

Bargain, O. and Kwenda, P. 2014. The Informal Sector Wage Gap: New Evidence Using Quantile Estimations on Panel Data. Economic Development and Cultural Change 63 (1): 117 - 153.

Bellmann, L., Estrin, S., Lehmann, H. and Wadsworth, J. 1995. The Eastern German Labour Market in Transition: Gross Flow Estimates from Panel Data. Journal of Comparative Economics, vol.20, n.1, 137-170.

Bernabè, S. and Stampini, M. 2009. Labour mobility during transition: Evidence from Georgia. Economics of Transition 17 (2): 377 - 409.

Chen, M.A. 2006. Rethinking the informal economy: linkages with the formal economy and the formal regulatory environment, in: Guha-Khasnobis, B., Kanbur, R. and Ostrom, E. (Eds.) 2006. Linking the Formal and Informal Economy: Concepts and Policies. Oxford University Press.

Clark, K. and Summers, L. 1979. Labour Market Dynamics and Unemployment: a Reconsideration. Brookings Papers on Economic Activity, Spring 13 - 60.

Constant, A., Kahanec, M. and Zimmermann, K.F. 2012. The Russian-Ukrainian Earnings Divide. Economics of Transition 20 (1): 1 - 35.

Cunningham, W. V. and Maloney, W. F. 2001. Heterogeneity among Mexico's Microenterprises: An Application of Cluster and Factor Analysis. Economic Development and Cultural Change 50 (1): $131-156$.

Earle, J. and Sakova, Z. 2000. Business start-ups or disguised unemployment? Evidence on the character of self-employment from transition economies. Labour Economics 7 (5): 575 - 601.

Fields, G. S. 1990. Labour market modelling and the urban informal sector: theory and evidence. In: D. Thurnham, B. Salomé and A. Schwarz (eds.) The Informal Sector Revisited, OECD. Paris.

Guasch, J. L. 1999. Labor market reforms and job creation: the unfinished agenda in Latin America and the Caribbean Countries. Washington D.C.: World Bank. 
Guha-Khasnobis, B., Kanbur, R. and Ostrom, E. (Eds.) 2006. Linking the Formal and Informal Economy: Concepts and Policies. Oxford University Press.

Harris, J. R. and Todaro, M.P. 1970. Migration, Unemployment and Development: A Two Sector Analysis. American Economic Review 60: 126-142.

Kanbur, R. 2015. Informality: Causes, Consequences and Policy Responses (March). CEPR Discussion Paper No. DP10509.

Kanbur, R. 2009. Conceptualising Informality: Regulation and Enforcement. Ithaca, New York, February, mimeo.

La Porta, R. and Shleifer, A. 2008. The Unofficial Economy and Economic Development. Brookings Papers on Economic Activity, Fall: 275 - 352.

Lehmann, H. 2015. Informal Employment in Transition Countries: Empirical Evidence and Research Challenges. Comparative Economic Studies 57 (1): 1-30.

Lehmann, H. and Zaiceva, A. 2013. Informal Employment in Russia: Incidence, Determinants and Labor Market Segmentation. University of Bologna, Department of Economics, Working Paper DSE No. 903.

Lehmann, H., Muravyev, A. and Zimmermann, K.F. 2012. The Ukrainian Longitudinal Monitoring Survey: Towards a better Understanding of Labor Markets in Transition. IZA Journal of Labor and Development 1:9.

Lehmann, H. and Pignatti, N. 2007. Informal Employment and Labor Market Segmentation in Transition Economies: Evidence from Ukraine. IZA Discussion Paper No. 3269. Institute for the Study of Labor, IZA, Bonn.

Lehmann, H., Pignatti, N. and J. Wadsworth. 2006. The Incidence and Cost of Job Loss in the Ukrainian labor market. Journal of Comparative Economics 34 (1): 248 - 271.

Maloney, W.F. 1999. Does Informality Imply Segmentation in Urban Labor Markets? Evidence from Sectoral Transitions in Mexico. The World Bank Economic Review 13 (2): 275 - 302.

Maloney, W. F. 2004. Informality Revisited. World Development 32: 1159-1178. 
Pagés, C. and Stampini, M. 2009. No Education, no Good Jobs? Evidence on the Relationship between Education and Labor Market Segmentation. Journal of Comparative Economics 37 (2): 387 401.

Perry, G., Maloney, W. Arias, O. Fajnzylber, P. Mason, A. and Saavedra-Chanduvi, J. 2007. Informality: Exit and Exclusion. Washington DC: World Bank.

Powell, D. 2016. Quantile regression with nonadditive fixed effects, RAND corporation discussion paper.

Slonimczyk, F. and Gimpelson, V. 2015. Informality and Mobility. Economics of Transition 23 (2): 299-341.

Solon, G. 1988. Self-Selection Bias in Longitudinal Estimation of Wage Gaps. Economic Letters 28 (3): $285-290$.

Tokman, V. 1986. The Informal Sector: Fifteen Later. Paper presented at the Conference "The Comparative Study of the Informal Sector.” Harper's Ferry, October.

Wooldridge, J.M. 2002. Econometric analysis of cross section and panel data, MIT Press.

Wooldridge, J.M. 1995. Selection corrections for panel data models under conditional mean independence assumptions. Journal of Econometrics 68: 115 - 132. 
Tables and Figures

Table 1. Descriptive statistics"

\begin{tabular}{|c|c|c|c|c|c|c|c|c|c|c|c|c|c|c|c|}
\hline & \multicolumn{5}{|c|}{ Entire Sample } & \multicolumn{5}{|c|}{ Females } & \multicolumn{5}{|c|}{ Males } \\
\hline & FS & VI & INVI & SEF & SEI & FS & VI & INVI & SEF & SEI & FS & VI & INVI & SEF & SEI \\
\hline $\begin{array}{l}\text { Mean hourly real } \\
\text { earnings (in Hryvnia) } \\
\text { (Std. Dev.) }\end{array}$ & $\begin{array}{c}2.63 \\
(2.81)\end{array}$ & $\begin{array}{c}2.77 \\
(2.72)\end{array}$ & $\begin{array}{l}2.29 \\
(2.3)\end{array}$ & $\begin{array}{l}4.79 \\
(6.26)\end{array}$ & $\begin{array}{l}4.04 \\
(5.57)\end{array}$ & $\begin{array}{c}2.27 \\
(2.48)\end{array}$ & $\begin{array}{c}2.54 \\
(3.12)\end{array}$ & $\begin{array}{c}1.9 \\
(2.06)\end{array}$ & $\begin{array}{c}4.12 \\
(3.59)\end{array}$ & $\begin{array}{l}3.38 \\
(3.92)\end{array}$ & $\begin{array}{l}3.08 \\
(3.1)\end{array}$ & $\begin{array}{l}3.01 \\
(2.2)\end{array}$ & $\begin{array}{c}2.69 \\
(2.46)\end{array}$ & $\begin{array}{c}5.35 \\
(7.81)\end{array}$ & $\begin{array}{l}4.33 \\
(6.16)\end{array}$ \\
\hline Female & 0.55 & 0.52 & 0.5 & 0.46 & 0.39 & 1 & 1 & 1 & 1 & 1 & 0 & 0 & 0 & 0 & 0 \\
\hline Ukrainian & 0.74 & 0.72 & 0.67 & 0.71 & 0.71 & 0.74 & 0.73 & 0.69 & 0.74 & 0.7 & 0.74 & 0.72 & 0.64 & 0.69 & 0.71 \\
\hline $\begin{array}{l}\text { Age } \\
\text { Marital status }\end{array}$ & 40.14 & 34.11 & 33.96 & 39.89 & 37.66 & 40.83 & 34.88 & 34.77 & 40.57 & 39.29 & 39.31 & 33.28 & 33.14 & 39.31 & 36.61 \\
\hline Married & 0.72 & 0.59 & 0.53 & 0.81 & 0.69 & 0.68 & 0.58 & 0.5 & 0.78 & 0.74 & 0.78 & 0.6 & 0.56 & 0.83 & 0.65 \\
\hline Single & 0.13 & 0.26 & 0.3 & 0.09 & 0.2 & 0.11 & 0.24 & 0.24 & 0.09 & 0.11 & 0.16 & 0.28 & 0.36 & 0.09 & 0.25 \\
\hline $\begin{array}{l}\text { Divorced or other status } \\
\text { Household characteristics }\end{array}$ & 0.14 & 0.15 & 0.17 & 0.11 & 0.12 & 0.21 & 0.18 & 0.26 & 0.13 & 0.15 & 0.06 & 0.12 & 0.07 & 0.09 & 0.1 \\
\hline Average household size & 3.58 & 3.79 & 3.7 & 3.62 & 3.72 & 3.5 & 3.63 & 3.56 & 3.63 & 3.59 & 3.67 & 3.96 & 3.83 & 3.62 & 3.8 \\
\hline $\begin{array}{l}\text { Average number of other } \\
\text { family members in } \\
\text { formal sector } \\
\text { Number of Dependent }\end{array}$ & 0.75 & 0.65 & 0.62 & 0.47 & 0.46 & 0.71 & 0.7 & 0.54 & 0.55 & 0.42 & 0.81 & 0.6 & 0.71 & 0.41 & 0.49 \\
\hline $\begin{array}{l}\text { children } \\
\text { Education }\end{array}$ & 0.28 & 0.33 & 0.3 & 0.38 & 0.33 & 0.28 & 0.35 & 0.36 & 0.28 & 0.31 & 0.29 & 0.31 & 0.25 & 0.46 & 0.34 \\
\hline Basic elementary and less & 0.03 & 0.09 & 0.08 & 0.02 & 0.08 & 0.02 & 0.01 & 0.06 & 0.01 & 0.08 & 0.03 & 0.17 & 0.10 & 0.03 & 0.08 \\
\hline $\begin{array}{l}\text { Vocational and } \\
\text { secondary }\end{array}$ & 0.75 & 0.78 & 0.86 & 0.72 & 0.81 & 0.71 & 0.77 & 0.85 & 0.78 & 0.81 & 0.79 & 0.78 & 0.87 & 0.66 & 0.80 \\
\hline $\begin{array}{l}\text { Higher } \\
\text { Sector }\end{array}$ & 0.22 & 0.14 & 0.06 & 0.26 & 0.11 & 0.26 & 0.21 & 0.09 & 0.22 & 0.10 & 0.18 & 0.05 & 0.03 & 0.30 & 0.11 \\
\hline $\begin{array}{l}\text { Agriculture, hunting and } \\
\text { fishing }\end{array}$ & 0.07 & 0.07 & 0.08 & 0.06 & 0.39 & 0.05 & 0.06 & 0.06 & 0.02 & 0.52 & 0.09 & 0.09 & 0.09 & 0.09 & 0.31 \\
\hline Industry $^{\mathrm{a}}$ & 0.27 & 0.13 & 0.16 & 0.04 & 0.04 & 0.20 & 0.08 & 0.11 & 0.01 & 0.01 & 0.37 & 0.18 & 0.21 & 0.07 & 0.05 \\
\hline Construction & 0.04 & 0.22 & 0.13 & 0.04 & 0.23 & 0.02 & 0.04 & 0.01 & 0.02 & 0.04 & 0.07 & 0.42 & 0.24 & 0.05 & 0.36 \\
\hline $\begin{array}{l}\text { Trade, Hotels and } \\
\text { Restaurants } \\
\text { Other Services }^{b}\end{array}$ & $\begin{array}{c}0.1 \\
0.18\end{array}$ & $\begin{array}{c}0.4 \\
0.16\end{array}$ & $\begin{array}{l}0.45 \\
0.17\end{array}$ & $\begin{array}{l}0.65 \\
020\end{array}$ & 0.16 & 0.12 & 0.62 & 0.62 & 0.81 & 0.22 & 0.08 & 0.17 & 0.27 & 0.53 & 0.13 \\
\hline Other Services ${ }^{0}$ & 0.18 & 0.16 & 0.17 & 0.20 & 0.16 & 0.17 & 0.18 & 0.16 & 0.12 & 0.19 & 0.20 & 0.14 & 0.18 & 0.26 & 0.14 \\
\hline
\end{tabular}




\begin{tabular}{|c|c|c|c|c|c|c|c|c|c|c|c|c|c|c|c|}
\hline & \multicolumn{5}{|c|}{ Entire Sample } & \multicolumn{5}{|c|}{ Females } & \multicolumn{5}{|c|}{ Males } \\
\hline & FS & VI & INVI & SEF & SEI & FS & VI & INVI & SEF & SEI & FS & VI & INVI & SEF & SEI \\
\hline $\begin{array}{l}\text { Education, Health and } \\
\text { Social protection }\end{array}$ & 0.25 & 0.01 & 0.02 & 0.02 & 0.01 & 0.38 & 0.02 & 0.03 & 0.03 & 0.02 & 0.10 & 0.00 & 0.00 & 0.01 & 0.01 \\
\hline Public administration & 0.08 & 0.00 & 0.00 & 0.00 & 0.00 & 0.07 & 0.00 & 0.00 & 0.00 & 0.00 & 0.10 & 0.00 & 0.00 & 0.00 & 0.00 \\
\hline \multicolumn{16}{|l|}{ Firm Size } \\
\hline Less than 5 & 0.05 & 0.36 & 0.31 & 0.86 & 0.88 & 0.07 & 0.38 & 0.43 & 0.88 & 0.96 & 0.03 & 0.33 & 0.19 & 0.84 & 0.82 \\
\hline $5-49$ & 0.30 & 0.52 & 0.50 & 0.09 & 0.08 & 0.34 & 0.50 & 0.45 & 0.05 & 0.01 & 0.25 & 0.55 & 0.55 & 0.12 & 0.13 \\
\hline $50-249$ & 0.30 & 0.10 & 0.15 & 0.02 & 0.01 & 0.29 & 0.10 & 0.10 & 0.02 & 0.02 & 0.31 & 0.12 & 0.21 & 0.03 & 0.01 \\
\hline 250-999 & 0.17 & 0.01 & 0.03 & 0.00 & 0.00 & 0.16 & 0.01 & 0.02 & 0.00 & 0.01 & 0.18 & 0.00 & 0.03 & 0.01 & 0.00 \\
\hline $1000+$ & 0.18 & 0.01 & 0.01 & 0.02 & 0.02 & 0.14 & 0.01 & 0.00 & 0.04 & 0.00 & 0.23 & 0.00 & 0.02 & 0.01 & 0.04 \\
\hline \multicolumn{16}{|l|}{ Macro-Regions } \\
\hline Kyiv & 0.06 & 0.09 & 0.04 & 0.02 & 0.03 & 0.06 & 0.12 & 0.04 & 0.02 & 0.05 & 0.05 & 0.05 & 0.04 & 0.02 & 0.02 \\
\hline Center North & 0.23 & 0.17 & 0.18 & 0.28 & 0.31 & 0.23 & 0.12 & 0.17 & 0.26 & 0.29 & 0.23 & 0.22 & 0.19 & 0.30 & 0.32 \\
\hline East & 0.38 & 0.38 & 0.42 & 0.36 & 0.31 & 0.36 & 0.42 & 0.44 & 0.36 & 0.31 & 0.40 & 0.35 & 0.40 & 0.36 & 0.31 \\
\hline South & 0.13 & 0.12 & 0.23 & 0.16 & 0.26 & 0.14 & 0.10 & 0.21 & 0.13 & 0.29 & 0.13 & 0.15 & 0.26 & 0.18 & 0.24 \\
\hline West & 0.20 & 0.24 & 0.13 & 0.17 & 0.10 & 0.20 & 0.25 & 0.14 & 0.22 & 0.07 & 0.19 & 0.23 & 0.13 & 0.13 & 0.11 \\
\hline Number of Observations & 6817 & 162 & 434 & 281 & 275 & 3736 & 84 & 219 & 129 & 108 & 3081 & 78 & 215 & 152 & 167 \\
\hline
\end{tabular}

Source: Authors' calculations based on ULMS.

* averaged over 2003, 2004 and 2007.

a Includes: Mining and Manufacturing.

b Includes: Energy gas water; Transportation; Financial and real estate; Other services.

Legend: FS - Formal Salaried; VI - Voluntary Informal Salaried; INVI - Involuntary Informal Salaried; SEF Self-Employed Formal; SEI - Self-Employed Informal. 
Table 2. Multinomial Logit of Workers' Status - Odds Ratios

\begin{tabular}{|c|c|c|c|c|}
\hline & VI & INVI & SEF & SEI \\
\hline \multicolumn{5}{|l|}{ Demographics: Ref. Male, Non-Ukrainian, Not Married } \\
\hline \multirow[t]{2}{*}{ Female } & 0.984 & 0.806 & $0.249 * * *$ & $0.450 * * *$ \\
\hline & $(0.190)$ & $(0.109)$ & $(0.052)$ & $(0.095)$ \\
\hline \multirow[t]{2}{*}{ Ukrainian } & 0.868 & 0.864 & 0.876 & 0.809 \\
\hline & $(0.189)$ & $(0.122)$ & $(0.197)$ & $(0.186)$ \\
\hline \multirow[t]{2}{*}{ Age } & $0.882 * *$ & $0.905 * *$ & 1.055 & 0.918 \\
\hline & $(0.056)$ & $(0.039)$ & $(0.074)$ & $(0.065)$ \\
\hline \multirow[t]{2}{*}{ Age squared/100 } & 1.131 & 1.097 & 0.942 & 1.096 \\
\hline & $(0.097)$ & $(0.063)$ & $(0.085)$ & $(0.102)$ \\
\hline \multirow[t]{2}{*}{ Married } & 0.845 & $0.624 * * *$ & $1.794 * *$ & 0.870 \\
\hline & $(0.188)$ & $(0.093)$ & $(0.433)$ & $(0.201)$ \\
\hline \multirow[t]{2}{*}{ Average household size } & 1.084 & 1.078 & 1.001 & $1.269 * * *$ \\
\hline & $(0.091)$ & $(0.050)$ & $(0.079)$ & $(0.100)$ \\
\hline \multirow[t]{2}{*}{ Av. n. of other family members in formal sector } & $0.790 *$ & $0.760 * * *$ & $0.653 * * *$ & $0.571 * * *$ \\
\hline & $(0.100)$ & $(0.063)$ & $(0.089)$ & $(0.079)$ \\
\hline \multirow[t]{2}{*}{ Number of dependent children } & 1.152 & 1.162 & 1.181 & 0.729 \\
\hline & $(0.261)$ & $(0.189)$ & $(0.263)$ & $(0.181)$ \\
\hline \multicolumn{5}{|l|}{ Education: Ref. Basic elementary and less } \\
\hline \multirow[t]{2}{*}{ Vocational and secondary } & 0.543 & $0.631 * *$ & 0.853 & 0.700 \\
\hline & $(0.203)$ & $(0.133)$ & $(0.398)$ & $(0.269)$ \\
\hline \multirow[t]{2}{*}{ Higher } & $0.478 *$ & $0.241 * * *$ & $2.434 *$ & 0.700 \\
\hline & $(0.206)$ & $(0.070)$ & $(1.215)$ & $(0.316)$ \\
\hline \multicolumn{5}{|l|}{ Sector: Ref. Agriculture, Hunting and Fishing } \\
\hline \multirow[t]{2}{*}{ Industry ${ }^{\mathrm{a}}$} & 0.999 & 1.177 & $0.330 * *$ & $0.046 * * *$ \\
\hline & $(0.407)$ & $(0.296)$ & $(0.175)$ & $(0.021)$ \\
\hline \multirow[t]{2}{*}{ Construction } & $4.455 * * *$ & $2.469 * * *$ & 1.399 & 1.501 \\
\hline & $(1.635)$ & $(0.641)$ & $(0.672)$ & $(0.440)$ \\
\hline \multirow[t]{2}{*}{ Trade, Hotels and Restaurants } & 1.488 & $2.110 * * *$ & $4.194 * * *$ & $0.093 * * *$ \\
\hline & $(0.505)$ & $(0.477)$ & $(1.412)$ & $(0.028)$ \\
\hline \multirow[t]{2}{*}{ Services $^{b}$} & 0.578 & 0.767 & 0.948 & $0.099 * * *$ \\
\hline & $(0.211)$ & $(0.183)$ & $(0.337)$ & $(0.027)$ \\
\hline \multirow[t]{2}{*}{ Education, Health and Social protection } & $0.047 * * *$ & $0.081 * * *$ & $0.140 * *$ & $0.018 * * *$ \\
\hline & $(0.036)$ & $(0.035)$ & $(0.108)$ & $(0.010)$ \\
\hline \multirow[t]{2}{*}{ Public administration } & $0.000 * * *$ & $0.000 * * *$ & $0.000 * * *$ & $0.000 * * *$ \\
\hline & $(0.000)$ & $(0.000)$ & $(0.000)$ & $(0.000)$ \\
\hline Firm Size: Ref. Less than 5 & & & & \\
\hline $5-49$ & $0.251 * * *$ & $0.326 * * *$ & $0.019 * * *$ & $0.009 * * *$ \\
\hline & $(0.054)$ & $(0.050)$ & $(0.004)$ & $(0.002)$ \\
\hline $50-249$ & $0.059 * * *$ & $0.122 * * *$ & $0.007 * * *$ & $0.002 * * *$ \\
\hline & $(0.019)$ & $(0.024)$ & $(0.003)$ & $(0.001)$ \\
\hline 250-999 & $0.006^{* * *}$ & $0.030 * * *$ & $0.003 * * *$ & $0.001 * * *$ \\
\hline & $(0.006)$ & $(0.011)$ & $(0.003)$ & $(0.001)$ \\
\hline $1000+$ & $0.004 * * *$ & $0.010 * * *$ & $0.017 * * *$ & $0.008 * * *$ \\
\hline & $(0.005)$ & $(0.005)$ & $(0.009)$ & $(0.004)$ \\
\hline Macro-Region: Ref. Kyiv & & & & \\
\hline Center North & $0.348 * * *$ & 0.832 & 2.061 & 0.948 \\
\hline & $(0.142)$ & $(0.280)$ & $(1.139)$ & $(0.543)$ \\
\hline East & 0.702 & 1.678 & 2.305 & 1.091 \\
\hline & $(0.255)$ & $(0.538)$ & $(1.266)$ & $(0.640)$ \\
\hline South & $0.422 * *$ & $1.775^{*}$ & 2.240 & 0.999 \\
\hline & $(0.175)$ & $(0.597)$ & $(1.277)$ & $(0.612)$ \\
\hline West & 0.612 & 0.788 & 1.926 & $0.366^{*}$ \\
\hline & $(0.238)$ & $(0.272)$ & $(1.137)$ & $(0.223)$ \\
\hline Pseudo R2 & 0.41 & & N. Obs. & 7,969 \\
\hline
\end{tabular}

Source: Authors' calculations based on ULMS data.

Clustered standard errors (individual level) in parentheses - * significant at $10 \% * *$ significant at $5 \% * * *$ significant at $1 \%$

${ }^{\text {a }}$ Includes: Mining and Manufacturing; ${ }^{\mathrm{b}}$ Includes: Energy gas water; Transportation; Financial and real estate; Other services.

Legend: VI - Voluntary Informal Salaried; INVI - Involuntary Informal Salaried; SEF Self-Employed Formal; SEI -

Self-Employed Informal NOTE: Multinomial logit with base outcome = being a formal salaried worker. 
Table 3. Transition matrices (entire sample - with (A) and without (B) round-trippers):

2003-2004

A. 2003-2004

\begin{tabular}{lcccccccc}
\hline & FS & VI & INVI & SEF & SEI & UN & OLF & Pi. \\
\hline FS & $\mathbf{0 . 8 6}$ & 0.01 & 0.02 & 0.01 & 0.00 & 0.04 & 0.06 & $\mathbf{0 . 4 9}$ \\
\hline & 0.01 & 0.00 & 0.00 & 0.00 & 0.00 & 0.00 & 0.01 & \\
\hline VI & 0.36 & $\mathbf{0 . 2 5}$ & 0.27 & 0.05 & 0.00 & 0.02 & 0.04 & $\mathbf{0 . 0 1}$ \\
\hline & 0.07 & 0.06 & 0.06 & 0.03 & 0.00 & 0.02 & 0.02 & \\
\hline INVI & 0.26 & 0.03 & $\mathbf{0 . 4 3}$ & 0.02 & 0.06 & 0.11 & 0.10 & $\mathbf{0 . 0 2}$ \\
\hline & 0.04 & 0.02 & 0.05 & 0.01 & 0.02 & 0.03 & 0.03 & \\
\hline SEF & 0.06 & 0.01 & 0.00 & $\mathbf{0 . 7 9}$ & 0.06 & 0.03 & 0.05 & $\mathbf{0 . 0 2}$ \\
\hline & 0.02 & 0.01 & 0.00 & 0.05 & 0.02 & 0.02 & 0.02 & \\
\hline SEI & 0.08 & 0.08 & 0.07 & 0.07 & $\mathbf{0 . 4 8}$ & 0.15 & 0.08 & $\mathbf{0 . 0 1}$ \\
\hline & 0.03 & 0.03 & 0.04 & 0.03 & 0.07 & 0.04 & 0.04 & \\
\hline UN & 0.26 & 0.03 & 0.08 & 0.01 & 0.03 & $\mathbf{0 . 3 4}$ & 0.24 & $\mathbf{0 . 1 3}$ \\
\hline & 0.02 & 0.01 & 0.01 & 0.00 & 0.01 & 0.02 & 0.02 & \\
\hline OLF & 0.10 & 0.02 & 0.02 & 0.01 & 0.00 & 0.12 & $\mathbf{0 . 7 4}$ & $\mathbf{0 . 3 2}$ \\
\hline & 0.01 & 0.00 & 0.00 & 0.00 & 0.00 & 0.01 & 0.01 & \\
\hline P.j & $\mathbf{0 . 5 0}$ & $\mathbf{0 . 0 2}$ & $\mathbf{0 . 0 4}$ & $\mathbf{0 . 0 2}$ & $\mathbf{0 . 0 1}$ & $\mathbf{0 . 1 1}$ & $\mathbf{0 . 3 0}$ & \\
\hline N & 5,103 & & & & & & & \\
\hline
\end{tabular}

B. 2003-2004

\begin{tabular}{lcccccccc}
\hline & FS & VI & INVI & SEF & SEI & UN & OLF & Pi. \\
\hline FS & $\mathbf{0 . 8 5}$ & 0.01 & 0.02 & 0.01 & 0.00 & 0.04 & 0.07 & $\mathbf{0 . 4 8}$ \\
\hline & 0.01 & 0.00 & 0.00 & 0.00 & 0.00 & 0.00 & 0.01 & \\
\hline VI & 0.39 & $\mathbf{0 . 2 0}$ & 0.29 & 0.06 & 0.00 & 0.02 & 0.04 & $\mathbf{0 . 0 1}$ \\
\hline INVI & 0.07 & 0.06 & 0.06 & 0.03 & 0.00 & 0.02 & 0.03 & \\
\hline & 0.28 & 0.03 & $\mathbf{0 . 4 0}$ & 0.02 & 0.06 & 0.11 & 0.10 & $\mathbf{0 . 0 2}$ \\
\hline SEF & 0.04 & 0.02 & 0.05 & 0.02 & 0.02 & 0.03 & 0.03 & \\
\hline & 0.06 & 0.01 & 0.00 & $\mathbf{0 . 7 8}$ & 0.06 & 0.04 & 0.05 & $\mathbf{0 . 0 2}$ \\
\hline SEI & 0.03 & 0.01 & 0.00 & 0.04 & 0.03 & 0.02 & 0.02 & \\
\hline & 0.09 & 0.09 & 0.07 & 0.07 & $\mathbf{0 . 4 3}$ & 0.16 & 0.09 & $\mathbf{0 . 0 1}$ \\
\hline UN & 0.04 & 0.04 & 0.03 & 0.03 & 0.06 & 0.05 & 0.03 & \\
\hline & 0.27 & 0.04 & 0.08 & 0.01 & 0.03 & $\mathbf{0 . 3 3}$ & 0.25 & $\mathbf{0 . 1 3}$ \\
\hline OLF & 0.02 & 0.01 & 0.01 & 0.00 & 0.01 & 0.02 & 0.02 & \\
\hline & 0.10 & 0.02 & 0.02 & 0.01 & 0.00 & 0.12 & $\mathbf{0 . 7 3}$ & $\mathbf{0 . 3 3}$ \\
\hline P.j & 0.01 & 0.00 & 0.00 & 0.00 & 0.00 & 0.01 & 0.01 & \\
\hline N & $\mathbf{0 . 4 9}$ & $\mathbf{0 . 0 2}$ & $\mathbf{0 . 0 4}$ & $\mathbf{0 . 0 2}$ & $\mathbf{0 . 0 1}$ & $\mathbf{0 . 1 1}$ & $\mathbf{0 . 3 1}$ & \\
\hline S & 4,903 & & & & & & & \\
\hline
\end{tabular}

Source: Authors' calculations based on ULMS.

Legend: FS - Formal Salaried; VI - Voluntary Informal Salaried; INVI - Involuntary Informal Salaried; SEF Self-Employed Formal; SEI - Self-Employed Informal.

Notes: Standard errors in Italic, bootstrapped with 1000 repetitions.

"Round-trippers" are persons who leave and return to the origin state over the given period.

Pi. is the relative size of a sector at the beginning of the period;

$\mathbf{P . j}$ is the relative size of a sector at the end of a period. 
Table 4. Transition matrices (entire sample - with (A) and without (B) round-trippers): 2003-2007

\begin{tabular}{|c|c|c|c|c|c|c|c|c|}
\hline \multicolumn{9}{|c|}{ A. 2003-2007 } \\
\hline & FS & VI & INVI & SEF & SEI & $\mathbf{U N}$ & OLF & Pi. \\
\hline \multirow[t]{2}{*}{ FS } & 0.77 & 0.01 & 0.02 & 0.01 & 0.02 & 0.04 & 0.13 & 0.52 \\
\hline & 0.01 & 0.00 & 0.00 & 0.00 & 0.00 & 0.00 & 0.01 & \\
\hline \multirow[t]{2}{*}{ VI } & 0.43 & 0.11 & 0.20 & 0.11 & 0.05 & 0.02 & 0.07 & 0.01 \\
\hline & 0.08 & 0.05 & 0.06 & 0.05 & 0.03 & 0.02 & 0.04 & \\
\hline \multirow[t]{2}{*}{ INVI } & 0.38 & 0.04 & 0.19 & 0.06 & 0.10 & 0.08 & 0.16 & 0.02 \\
\hline & 0.05 & 0.02 & 0.05 & 0.03 & 0.03 & 0.03 & 0.04 & \\
\hline \multirow[t]{2}{*}{ SEF } & 0.13 & 0.01 & 0.05 & 0.67 & 0.03 & 0.01 & 0.09 & 0.02 \\
\hline & 0.04 & 0.01 & 0.03 & 0.05 & 0.02 & 0.01 & 0.03 & \\
\hline \multirow[t]{2}{*}{ SEI } & 0.31 & 0.03 & 0.08 & 0.10 & 0.31 & 0.08 & 0.10 & 0.01 \\
\hline & 0.07 & 0.03 & 0.04 & 0.05 & 0.08 & 0.04 & 0.05 & \\
\hline \multirow[t]{2}{*}{$\mathbf{U N}$} & 0.39 & 0.02 & 0.10 & 0.02 & 0.06 & 0.11 & 0.29 & 0.12 \\
\hline & 0.02 & 0.01 & 0.01 & 0.01 & 0.01 & 0.01 & 0.02 & \\
\hline \multirow[t]{2}{*}{ OLF } & 0.32 & 0.02 & 0.04 & 0.03 & 0.03 & 0.09 & 0.48 & 0.30 \\
\hline & 0.01 & 0.00 & 0.01 & 0.00 & 0.00 & 0.01 & 0.01 & \\
\hline P.j & 0.56 & 0.01 & 0.04 & 0.03 & 0.03 & 0.06 & 0.25 & \\
\hline $\mathbf{N}$ & 3,935 & & & & & & & \\
\hline
\end{tabular}

\begin{tabular}{|c|c|c|c|c|c|c|c|c|}
\hline \multicolumn{9}{|c|}{ B. 2003-2007 } \\
\hline & FS & VI & INVI & SEF & SEI & $\mathbf{U N}$ & OLF & Pi. \\
\hline \multirow[t]{2}{*}{ FS } & 0.71 & 0.01 & 0.03 & 0.02 & 0.02 & 0.05 & 0.17 & 0.48 \\
\hline & 0.01 & 0.00 & 0.00 & 0.00 & 0.00 & 0.01 & 0.01 & \\
\hline \multirow[t]{2}{*}{ VI } & 0.49 & 0.00 & 0.23 & 0.13 & 0.05 & 0.03 & 0.08 & 0.01 \\
\hline & 0.08 & 0.00 & 0.07 & 0.06 & 0.04 & 0.02 & 0.04 & \\
\hline \multirow[t]{2}{*}{ INVI } & 0.42 & 0.04 & 0.08 & 0.07 & 0.11 & 0.08 & 0.18 & 0.02 \\
\hline & 0.06 & 0.03 & 0.03 & 0.03 & 0.03 & 0.03 & 0.05 & \\
\hline \multirow[t]{2}{*}{ SEF } & 0.15 & 0.02 & 0.06 & 0.62 & 0.03 & 0.02 & 0.11 & 0.02 \\
\hline & 0.04 & 0.01 & 0.03 & 0.06 & 0.02 & 0.02 & 0.04 & \\
\hline \multirow[t]{2}{*}{ SEI } & 0.36 & 0.03 & 0.09 & 0.12 & 0.18 & 0.09 & 0.12 & 0.01 \\
\hline & 0.09 & 0.03 & 0.05 & 0.05 & 0.06 & 0.05 & 0.06 & \\
\hline \multirow[t]{2}{*}{$\mathbf{U N}$} & 0.43 & 0.03 & 0.10 & 0.03 & 0.07 & 0.03 & 0.32 & 0.14 \\
\hline & 0.03 & 0.01 & 0.01 & 0.01 & 0.01 & 0.01 & 0.02 & \\
\hline \multirow[t]{2}{*}{ OLF } & 0.36 & 0.02 & 0.05 & 0.03 & 0.03 & 0.10 & 0.41 & 0.32 \\
\hline & 0.01 & 0.00 & 0.01 & 0.01 & 0.01 & 0.01 & 0.01 & \\
\hline P.j & 0.54 & 0.01 & 0.05 & 0.04 & 0.03 & 0.06 & 0.26 & \\
\hline $\mathbf{N}$ & 3,273 & & & & & & & \\
\hline
\end{tabular}

Source: Authors' calculations based on ULMS.

Legend: FS - Formal Salaried; VI - Voluntary Informal Salaried; INVI - Involuntary Informal Salaried; SEF Self-Employed Formal; SEI - Self-Employed Informal.

Notes: Standard errors in Italic, bootstrapped with 1000 repetitions.

"Round-trippers" are persons who leave and return to the origin state over the given period.

Pi. is the relative size of a sector at the beginning of the period;

$\mathbf{P . j}$ is the relative size of a sector at the end of a period. 
Table 5. Determinants of log hourly real earnings - OLS and Fixed Effects: 2003-2007

\begin{tabular}{|c|c|c|c|c|c|c|c|c|c|}
\hline & \multicolumn{3}{|c|}{ Entire Sample } & \multicolumn{3}{|c|}{ Women } & \multicolumn{3}{|c|}{ Men } \\
\hline & $\begin{array}{l}\text { Pooled } \\
\text { OLS }\end{array}$ & $\begin{array}{c}\text { Pooled OLS } \\
\text { with Heckman } \\
\text { correction }\end{array}$ & Fixed Effects & $\begin{array}{c}\text { Pooled } \\
\text { OLS }\end{array}$ & $\begin{array}{c}\text { Pooled OLS } \\
\text { with Heckman } \\
\text { correction }\end{array}$ & Fixed Effects & $\begin{array}{l}\text { Pooled } \\
\text { OLS }\end{array}$ & $\begin{array}{c}\text { Pooled OLS } \\
\text { with Heckman } \\
\text { correction }\end{array}$ & Fixed Effects \\
\hline Female & $\begin{array}{c}-0.252 * * * \\
(0.015)\end{array}$ & $\begin{array}{c}-0.259^{* * *} \\
(0.021)\end{array}$ & & & & & & & \\
\hline Ukrainian & $\begin{array}{c}-0.035^{* *} \\
(0.017)\end{array}$ & $\begin{array}{c}-0.035^{* *} \\
(0.014)\end{array}$ & & $\begin{array}{c}-0.043 * * \\
(0.021)\end{array}$ & $\begin{array}{c}-0.043 * * \\
(0.017)\end{array}$ & & $\begin{array}{c}-0.026 \\
(0.027)\end{array}$ & $\begin{array}{l}-0.027 \\
(0.023)\end{array}$ & \\
\hline Age & $\begin{array}{c}0.013 * * * \\
(0.005)\end{array}$ & $\begin{array}{c}0.019 \\
(0.014)\end{array}$ & $\begin{array}{c}0.265^{* * *} \\
(0.017)\end{array}$ & $\begin{array}{l}0.013^{*} \\
(0.007)\end{array}$ & $\begin{array}{c}0.013 \\
(0.016)\end{array}$ & $\begin{array}{c}0.278 * * * \\
(0.024)\end{array}$ & $\begin{array}{c}0.009 \\
(0.007)\end{array}$ & $\begin{array}{c}0.010 \\
(0.018)\end{array}$ & $\begin{array}{c}0.250 * * * \\
(0.025)\end{array}$ \\
\hline Age Squared/100 & $\begin{array}{c}-0.019 * * * \\
(0.006)\end{array}$ & $\begin{array}{l}-0.027 \\
(0.018)\end{array}$ & $\begin{array}{c}-0.093 * * * \\
(0.020)\end{array}$ & $\begin{array}{l}-0.017^{*} \\
(0.009)\end{array}$ & $\begin{array}{l}-0.017 \\
(0.020)\end{array}$ & $\begin{array}{c}-0.103 * * * \\
(0.026)\end{array}$ & $\begin{array}{l}-0.018^{*} \\
(0.009)\end{array}$ & $\begin{array}{l}-0.019 \\
(0.024)\end{array}$ & $\begin{array}{c}-0.081 * * * \\
(0.031)\end{array}$ \\
\hline Vocational and Secondary & $\begin{array}{c}0.019 \\
(0.037)\end{array}$ & $\begin{array}{c}0.035 \\
(0.044)\end{array}$ & $\begin{array}{l}-0.023 \\
(0.075)\end{array}$ & $\begin{array}{c}0.004 \\
(0.052)\end{array}$ & $\begin{array}{c}0.002 \\
(0.053)\end{array}$ & $\begin{array}{l}-0.059 \\
(0.071)\end{array}$ & $\begin{array}{c}0.046 \\
(0.049)\end{array}$ & $\begin{array}{c}0.057 \\
(0.068)\end{array}$ & $\begin{array}{c}0.004 \\
(0.110)\end{array}$ \\
\hline Higher & $\begin{array}{c}0.298 * * * \\
(0.042)\end{array}$ & $\begin{array}{c}0.325 * * * \\
(0.065)\end{array}$ & $\begin{array}{c}0.185 \\
(0.114)\end{array}$ & $\begin{array}{c}0.327 * * * \\
(0.057)\end{array}$ & $\begin{array}{c}0.326^{* * *} \\
(0.069)\end{array}$ & $\begin{array}{c}0.200 \\
(0.136)\end{array}$ & $\begin{array}{c}0.260 * * * \\
(0.058)\end{array}$ & $\begin{array}{c}0.274 * * * \\
(0.094)\end{array}$ & $\begin{array}{c}0.123 \\
(0.167)\end{array}$ \\
\hline Tenure & $\begin{array}{c}0.010^{* * *} \\
(0.003)\end{array}$ & $\begin{array}{c}0.010^{* * * *} \\
(0.002)\end{array}$ & $\begin{array}{l}-0.006 \\
(0.004)\end{array}$ & $\begin{array}{c}0.009 * * * \\
(0.003)\end{array}$ & $\begin{array}{c}0.009^{* * *} \\
(0.003)\end{array}$ & $\begin{array}{l}-0.010^{*} \\
(0.005)\end{array}$ & $\begin{array}{c}0.009 * * \\
(0.004)\end{array}$ & $\begin{array}{c}0.009 * * \\
(0.004)\end{array}$ & $\begin{array}{c}0.000 \\
(0.006)\end{array}$ \\
\hline Tenure Squared/100 & $\begin{array}{c}-0.019 * * \\
(0.008)\end{array}$ & $\begin{array}{c}-0.019 * * * \\
(0.007)\end{array}$ & $\begin{array}{c}0.011 \\
(0.012)\end{array}$ & $\begin{array}{l}-0.018^{*} \\
(0.009)\end{array}$ & $\begin{array}{c}-0.018^{* *} \\
(0.008)\end{array}$ & $\begin{array}{c}0.020 \\
(0.015)\end{array}$ & $\begin{array}{l}-0.016 \\
(0.013)\end{array}$ & $\begin{array}{l}-0.016 \\
(0.012)\end{array}$ & $\begin{array}{l}-0.003 \\
(0.019)\end{array}$ \\
\hline Part Time & $\begin{array}{c}0.136^{* * * *} \\
(0.040)\end{array}$ & $\begin{array}{c}0.135 * * * \\
(0.038)\end{array}$ & $\begin{array}{c}0.206 * * * \\
(0.051)\end{array}$ & $\begin{array}{c}0.148 * * * \\
(0.044)\end{array}$ & $\begin{array}{c}0.148 * * * \\
(0.042)\end{array}$ & $\begin{array}{c}0.181 * * * \\
(0.054)\end{array}$ & $\begin{array}{c}0.084 \\
(0.082)\end{array}$ & $\begin{array}{c}0.083 \\
(0.077)\end{array}$ & $\begin{array}{c}0.257 * * \\
(0.112)\end{array}$ \\
\hline Married & $\begin{array}{l}0.028^{*} \\
(0.016)\end{array}$ & $\begin{array}{l}0.027^{*} \\
(0.014)\end{array}$ & $\begin{array}{c}0.036 \\
(0.035)\end{array}$ & $\begin{array}{l}-0.009 \\
(0.019)\end{array}$ & $\begin{array}{l}-0.009 \\
(0.020)\end{array}$ & $\begin{array}{c}0.039 \\
(0.043)\end{array}$ & $\begin{array}{c}0.111^{* * *} \\
(0.028)\end{array}$ & $\begin{array}{c}0.114 * * \\
(0.052)\end{array}$ & $\begin{array}{c}0.019 \\
(0.057)\end{array}$ \\
\hline Voluntary Informal & $\begin{array}{c}0.155^{* * *} * \\
(0.051)\end{array}$ & $\begin{array}{c}0.148 * * * \\
(0.051)\end{array}$ & $\begin{array}{l}0.199^{*} \\
(0.112)\end{array}$ & $\begin{array}{c}0.164 * * \\
(0.074)\end{array}$ & $\begin{array}{c}0.146^{* *} \\
(0.069)\end{array}$ & $\begin{array}{c}0.184 \\
(0.152)\end{array}$ & $\begin{array}{c}0.138 * * \\
(0.069)\end{array}$ & $\begin{array}{c}0.144 * * \\
(0.072)\end{array}$ & $\begin{array}{c}0.231 \\
(0.173)\end{array}$ \\
\hline Involuntary Informal & $\begin{array}{c}-0.066^{* *} \\
(0.032)\end{array}$ & $\begin{array}{c}-0.064 * * \\
(0.031)\end{array}$ & $\begin{array}{c}-0.074 \\
(0.051)\end{array}$ & $\begin{array}{l}-0.053 \\
(0.043)\end{array}$ & $\begin{array}{c}-0.050 \\
(0.041)\end{array}$ & $\begin{array}{l}-0.035 \\
(0.062)\end{array}$ & $\begin{array}{c}-0.076 \\
(0.046)\end{array}$ & $\begin{array}{l}-0.075 \\
(0.046)\end{array}$ & $\begin{array}{c}-0.150^{*} \\
(0.085)\end{array}$ \\
\hline Self-Employed Formal & $\begin{array}{c}0.417^{* * *} * \\
(0.054)\end{array}$ & $\begin{array}{c}0.422 * * * \\
(0.051)\end{array}$ & $\begin{array}{c}0.371^{* * *} \\
(0.116)\end{array}$ & $\begin{array}{c}0.502 * * * \\
(0.070)\end{array}$ & $\begin{array}{c}0.514^{* * *} \\
(0.069)\end{array}$ & $\begin{array}{c}0.290 * * \\
(0.133)\end{array}$ & $\begin{array}{c}0.358 * * * \\
(0.083)\end{array}$ & $\begin{array}{c}0.360 * * * \\
(0.080)\end{array}$ & $\begin{array}{c}0.480 * * \\
(0.209)\end{array}$ \\
\hline Self-Employed Informal & $\begin{array}{c}0.312 * * * \\
(0.066)\end{array}$ & $\begin{array}{c}0.312 * * * \\
(0.061)\end{array}$ & $\begin{array}{c}0.319 * * \\
(0.144)\end{array}$ & $\begin{array}{c}0.336^{* * *} \\
(0.115)\end{array}$ & $\begin{array}{c}0.338 * * * \\
(0.108)\end{array}$ & $\begin{array}{c}0.228 \\
(0.203)\end{array}$ & $\begin{array}{c}0.269 * * * \\
(0.084)\end{array}$ & $\begin{array}{c}0.269 * * * \\
(0.078)\end{array}$ & $\begin{array}{c}0.311 \\
(0.189)\end{array}$ \\
\hline Lambda & & $\begin{array}{c}0.038 \\
(0.088)\end{array}$ & & & $\begin{array}{l}-0.005 \\
(0.077)\end{array}$ & & & $\begin{array}{c}0.016 \\
(0.147)\end{array}$ & \\
\hline Additional controls ${ }^{\text {a }}$ & YES & YES & YES & YES & YES & YES & YES & YES & YES \\
\hline R2 & 0.43 & & 0.52 & 0.44 & & 0.54 & 0.40 & & 0.50 \\
\hline $\mathbf{N}$ & 7,486 & 7,469 & 7,486 & 4,041 & 4,031 & 4,041 & 3,445 & 3,438 & 3,445 \\
\hline
\end{tabular}

Source: Authors' calculations based on ULMS data

Robust standard errors in parentheses (OLS and Fixed Effects) 
Standard errors for the two-step Heckman selection model have been obtained by bootstrapping (1,000 repetitions).

* significant at $10 \% * *$ significant at 5\%*** significant at $1 \%$

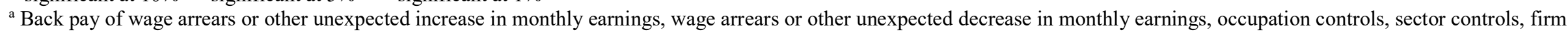
size controls and ownership controls.

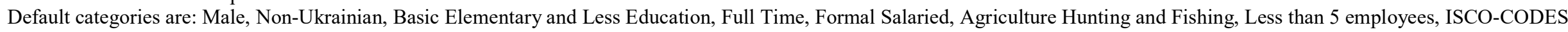
1-3, New Private Enterprise, Kyiv City. 
Table 6. Employment status and log hourly real earnings - Pooled Quantile Regressions: 2003-2007

\begin{tabular}{|c|c|c|c|c|c|c|c|c|c|}
\hline & q10 & $\mathbf{q 2 0}$ & q30 & $q 40$ & q50 & $q 60$ & q70 & q80 & q90 \\
\hline & \multicolumn{9}{|c|}{ Entire sample $(7,486$ obs. $)$} \\
\hline \multirow[t]{2}{*}{ Voluntary Informal } & 0.024 & 0.053 & 0.090 & $0.117 * *$ & $0.097^{*}$ & $0.164 * *$ & $0.179 * * *$ & $0.264 * * *$ & 0.205 \\
\hline & $(0.069)$ & $(0.082)$ & $(0.067)$ & $(0.051)$ & $(0.054)$ & $(0.068)$ & $(0.067)$ & $(0.085)$ & $(0.125)$ \\
\hline \multirow[t]{2}{*}{ Involuntary Informal } & $-0.119 * * *$ & $-0.163 * * *$ & $-0.118 * * *$ & $-0.119 * * *$ & $-0.083 * *$ & $-0.064 *$ & $-0.066^{*}$ & -0.028 & 0.008 \\
\hline & $(0.045)$ & $(0.039)$ & $(0.032)$ & $(0.038)$ & $(0.039)$ & $(0.038)$ & $(0.039)$ & $(0.049)$ & $(0.067)$ \\
\hline \multirow[t]{2}{*}{ Self-Employed Formal } & $0.153^{* *}$ & $0.247 * * *$ & $0.331 * * *$ & $0.408^{* * *}$ & $0.428 * * *$ & $0.471 * * *$ & $0.521 * * *$ & $0.566^{* * *}$ & $0.604 * * *$ \\
\hline & $(0.075)$ & $(0.067)$ & $(0.090)$ & $(0.054)$ & $(0.071)$ & $(0.054)$ & $(0.061)$ & $(0.063)$ & $(0.137)$ \\
\hline \multirow[t]{3}{*}{ Self-Employed Informal } & 0.079 & $0.154^{*}$ & $0.221 * * *$ & $0.242 * * *$ & $0.258 * * *$ & $0.328 * * *$ & $0.406^{* * *}$ & $0.402 * * *$ & $0.520 * * *$ \\
\hline & $(0.090)$ & $(0.087)$ & $(0.075)$ & $(0.072)$ & $(0.070)$ & $(0.084)$ & $(0.089)$ & $(0.070)$ & $(0.156)$ \\
\hline & \multicolumn{9}{|c|}{ Women $(4,041$ obs. $)$} \\
\hline \multirow[t]{2}{*}{ Voluntary Informal } & -0.011 & -0.045 & 0.068 & 0.144 & $0.144 * *$ & $0.169 * *$ & $0.169^{*}$ & $0.228 * *$ & 0.258 \\
\hline & $(0.092)$ & $(0.095)$ & $(0.109)$ & $(0.094)$ & $(0.072)$ & $(0.074)$ & $(0.093)$ & $(0.108)$ & $(0.176)$ \\
\hline \multirow[t]{2}{*}{ Involuntary Informal } & -0.033 & $-0.135^{* * *}$ & $-0.134 * * *$ & $-0.113 * *$ & $-0.095^{*}$ & -0.047 & -0.058 & -0.075 & 0.104 \\
\hline & $(0.066)$ & $(0.045)$ & $(0.043)$ & $(0.050)$ & $(0.052)$ & $(0.054)$ & $(0.051)$ & $(0.071)$ & $(0.096)$ \\
\hline \multirow{2}{*}{ Self-Employed Formal } & $0.258^{* * *}$ & $0.279 * * *$ & $0.389 * * *$ & $0.423^{* * *}$ & $0.478 * * *$ & $0.590 * * *$ & $0.577 * * *$ & $0.627 * * *$ & $0.798 * * *$ \\
\hline & $(0.093)$ & $(0.082)$ & $(0.113)$ & $(0.083)$ & $(0.079)$ & $(0.076)$ & $(0.099)$ & $(0.085)$ & $(0.172)$ \\
\hline \multirow[t]{3}{*}{ Self-Employed Informal } & -0.040 & 0.092 & 0.133 & 0.132 & $0.304 *$ & $0.383^{* *}$ & $0.507 * * *$ & $0.643 * * *$ & $0.693 * * *$ \\
\hline & $(0.154)$ & $(0.137)$ & $(0.119)$ & $(0.172)$ & $(0.181)$ & $(0.169)$ & $(0.155)$ & $(0.170)$ & $(0.189)$ \\
\hline & \multicolumn{9}{|c|}{ Men (3,445 obs.) } \\
\hline \multirow[t]{2}{*}{ Voluntary Informal } & 0.027 & 0.046 & 0.104 & 0.102 & 0.108 & 0.097 & 0.105 & $0.257 * *$ & 0.221 \\
\hline & $(0.113)$ & $(0.099)$ & $(0.090)$ & $(0.087)$ & $(0.086)$ & $(0.103)$ & $(0.116)$ & $(0.107)$ & $(0.151)$ \\
\hline \multirow{2}{*}{ Involuntary Informal } & $-0.132 * *$ & $-0.133 * *$ & $-0.108 * *$ & -0.089 & -0.097 & -0.024 & -0.070 & -0.005 & -0.017 \\
\hline & $(0.061)$ & $(0.067)$ & $(0.054)$ & $(0.060)$ & $(0.063)$ & $(0.058)$ & $(0.058)$ & $(0.062)$ & $(0.080)$ \\
\hline \multirow[t]{2}{*}{ Self-Employed Formal } & -0.000 & 0.110 & $0.266^{* *}$ & $0.398^{* * *}$ & $0.412 * * *$ & $0.442 * * *$ & $0.486^{* * *}$ & $0.498 * * *$ & $0.492 * * *$ \\
\hline & $(0.133)$ & $(0.108)$ & $(0.113)$ & $(0.112)$ & $(0.088)$ & $(0.091)$ & $(0.092)$ & $(0.082)$ & $(0.151)$ \\
\hline \multirow[t]{2}{*}{ Self-Employed Informal } & 0.125 & 0.078 & $0.183 *$ & $0.301 * * *$ & $0.296 * * *$ & $0.235 * * *$ & $0.315^{* * *}$ & $0.275^{* * *}$ & $0.283^{*}$ \\
\hline & $(0.118)$ & $(0.103)$ & $(0.105)$ & $(0.115)$ & $(0.086)$ & $(0.089)$ & $(0.100)$ & $(0.097)$ & $(0.170)$ \\
\hline Demographic controls ${ }^{a}$ & YES & YES & YES & YES & YES & YES & YES & YES & YES \\
\hline Additional controls ${ }^{b}$ & YES & YES & YES & YES & YES & YES & YES & YES & YES \\
\hline
\end{tabular}

Source: Authors' calculations based on ULMS data. Bootstrapped standard errors in parentheses (1,000 repetitions).

* significant at $10 \% * *$ significant at $5 \% * * *$ significant at $1 \%$.

a Female, Ukrainian, Age, Age Squared/10, Vocational and Secondary Education, Higher Education, Tenure, Tenure Squared/100, Part-Time, Married.

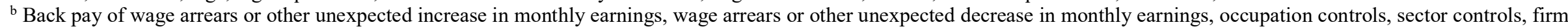
size controls and ownership controls.

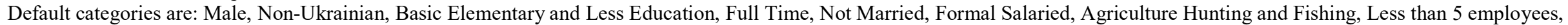

ISCO-CODES 1-3, New Private Enterprise, Kyiv City. 
Table 7. Employment status and log hourly real earnings - Fixed Effects Quantile Regressions: 2003-2007

\begin{tabular}{|c|c|c|c|c|c|c|c|c|c|}
\hline & q10 & q20 & q30 & $q 40$ & q50 & $q 60$ & q70 & q80 & $\mathbf{q 9 0}$ \\
\hline & \multicolumn{9}{|c|}{ Entire sample $(7,486$ obs. $)$} \\
\hline \multirow[t]{2}{*}{ Voluntary Informal } & 0.015 & $0.184 * * *$ & $0.197 * * *$ & $0.066^{* *}$ & $0.235^{* * *}$ & 0.065 & $0.293 * * *$ & $0.071^{* *}$ & $0.206^{* *}$ \\
\hline & $(0.050)$ & $(0.057)$ & $(0.013)$ & $(0.030)$ & $(0.050)$ & $(0.102)$ & $(0.067)$ & $(0.034)$ & $(0.102)$ \\
\hline \multirow[t]{2}{*}{ Involuntary Informal } & $-0.068^{* * *}$ & -0.055 & $-0.035^{*}$ & $-0.163 * * *$ & -0.011 & -0.022 & $-0.105^{* * *}$ & $-0.093 * * *$ & 0.032 \\
\hline & $(0.021)$ & $(0.040)$ & $(0.019)$ & $(0.038)$ & $(0.022)$ & $(0.026)$ & $(0.030)$ & $(0.023)$ & $(0.041)$ \\
\hline \multirow[t]{2}{*}{ Self-Employed Formal } & $0.286^{* * *}$ & $0.316^{* * *}$ & $0.516^{* * *}$ & $0.572 * * *$ & $0.564 * * *$ & $0.550 * * *$ & $0.296^{* *}$ & $0.619 * * *$ & $0.580 * * *$ \\
\hline & $(0.045)$ & $(0.032)$ & $(0.023)$ & $(0.019)$ & $(0.074)$ & $(0.076)$ & $(0.128)$ & $(0.040)$ & $(0.079)$ \\
\hline \multirow[t]{3}{*}{ Self-Employed Informal } & $0.372 * * *$ & $0.215^{* * *}$ & $0.458 * * *$ & $0.434 * * *$ & $0.437 * * *$ & $0.456 * * *$ & $0.675 * * *$ & $0.389 * * *$ & $0.468 * * *$ \\
\hline & $(0.129)$ & $(0.046)$ & $(0.046)$ & $(0.033)$ & $(0.080)$ & $(0.040)$ & $(0.074)$ & $(0.067)$ & $(0.076)$ \\
\hline & \multicolumn{9}{|c|}{ Women $(4,041$ obs. $)$} \\
\hline \multirow[t]{2}{*}{ Voluntary Informal } & -0.015 & $-0.117 * * *$ & $0.110 * * *$ & $0.163 * * *$ & $0.289^{* * *}$ & $0.084 * *$ & $0.241 * * *$ & -0.018 & $0.386 * * *$ \\
\hline & $(0.030)$ & $(0.026)$ & $(0.042)$ & $(0.026)$ & $(0.042)$ & $(0.041)$ & $(0.036)$ & $(0.097)$ & $(0.059)$ \\
\hline \multirow[t]{2}{*}{ Involuntary Informal } & -0.017 & 0.044 & $-0.065^{*}$ & $-0.108 * *$ & $-0.090 * * *$ & $-0.109 * * *$ & -0.009 & $-0.171 * * *$ & $-0.074 * * *$ \\
\hline & $(0.015)$ & $(0.063)$ & $(0.037)$ & $(0.055)$ & $(0.025)$ & $(0.023)$ & $(0.037)$ & $(0.064)$ & $(0.025)$ \\
\hline \multirow[t]{2}{*}{ Self-Employed Formal } & $0.255^{* * *}$ & $0.240^{* * *}$ & $0.608 * * *$ & $0.622 * * *$ & $0.594 * * *$ & $0.664 * * *$ & $0.801 * * *$ & $0.587 * * *$ & $0.543 * * *$ \\
\hline & $(0.050)$ & $(0.078)$ & $(0.046)$ & $(0.032)$ & $(0.041)$ & $(0.050)$ & $(0.024)$ & $(0.071)$ & $(0.084)$ \\
\hline \multirow{3}{*}{ Self-Employed Informal } & $0.123 * *$ & $0.380 * * *$ & $0.288 * * *$ & $0.260 * * *$ & $0.234 * * *$ & $0.495 * * *$ & $0.389 * * *$ & $0.424 * * *$ & $0.402 * * *$ \\
\hline & $(0.052)$ & $(0.135)$ & $(0.041)$ & $(0.040)$ & $(0.031)$ & $(0.020)$ & $(0.017)$ & $(0.066)$ & $(0.090)$ \\
\hline & \multicolumn{9}{|c|}{ Men $(3,445$ obs. $)$} \\
\hline \multirow[t]{2}{*}{ Voluntary Informal } & $0.201 * * *$ & $0.325 * * *$ & $0.347 * * *$ & $0.182 * * *$ & $0.134 * * *$ & $0.074 * * *$ & -0.000 & -0.056 & $0.183^{*}$ \\
\hline & $(0.064)$ & $(0.056)$ & $(0.066)$ & $(0.049)$ & $(0.048)$ & $(0.026)$ & $(0.102)$ & $(0.063)$ & $(0.101)$ \\
\hline \multirow{2}{*}{ Involuntary Informal } & -0.043 & $-0.084 * * *$ & $-0.186^{* * *}$ & $-0.135 * * *$ & 0.061 & 0.028 & -0.033 & -0.037 & -0.048 \\
\hline & $(0.032)$ & $(0.030)$ & $(0.038)$ & $(0.024)$ & $(0.057)$ & $(0.028)$ & $(0.050)$ & $(0.078)$ & $(0.059)$ \\
\hline \multirow{2}{*}{ Self-Employed Formal } & $0.136^{* *}$ & $0.274 * * *$ & $0.233 * * *$ & $0.367 * * *$ & $0.424 * * *$ & $0.434 * * *$ & $0.394 * * *$ & $0.537 * * *$ & $0.591 * * *$ \\
\hline & $(0.064)$ & $(0.037)$ & $(0.036)$ & $(0.018)$ & $(0.030)$ & $(0.050)$ & $(0.092)$ & $(0.048)$ & $(0.082)$ \\
\hline \multirow[t]{2}{*}{ Self-Employed Informal } & 0.169 & $0.337 * * *$ & $0.427 * * *$ & $0.391 * * *$ & $0.423 * * *$ & $0.330 * * *$ & $0.440 * * *$ & $0.409 * * *$ & $0.346^{* * *}$ \\
\hline & $(0.147)$ & $(0.032)$ & $(0.076)$ & $(0.030)$ & $(0.016)$ & $(0.045)$ & $(0.053)$ & $(0.063)$ & $(0.063)$ \\
\hline Demographic controls ${ }^{a}$ & YES & YES & YES & YES & YES & YES & YES & YES & YES \\
\hline Additional controls ${ }^{b}$ & YES & YES & YES & YES & YES & YES & YES & YES & YES \\
\hline
\end{tabular}

Source: Authors' calculations based on ULMS data. Bootstrapped standard errors in parentheses (1,000 repetitions).

* significant at $10 \% * *$ significant at $5 \% * * *$ significant at $1 \%$

a Age, Age Squared/10, Vocational and Secondary Education, Higher Education, Tenure, Tenure Squared/100, Part-Time, Married.

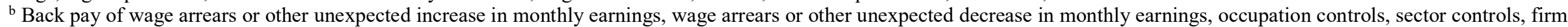
size controls and ownership controls.

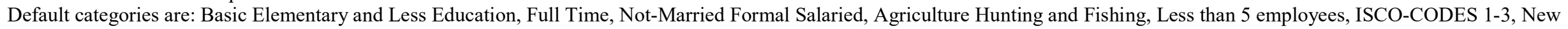
Private Enterprise, Kyiv City. 
FIGURES - EARNINGS DISTRIBUTIONS

Figure 1. Log real hourly earnings - entire sample - years 2003, 2004 and 2007

\section{Log real hourly earnings - all waves}

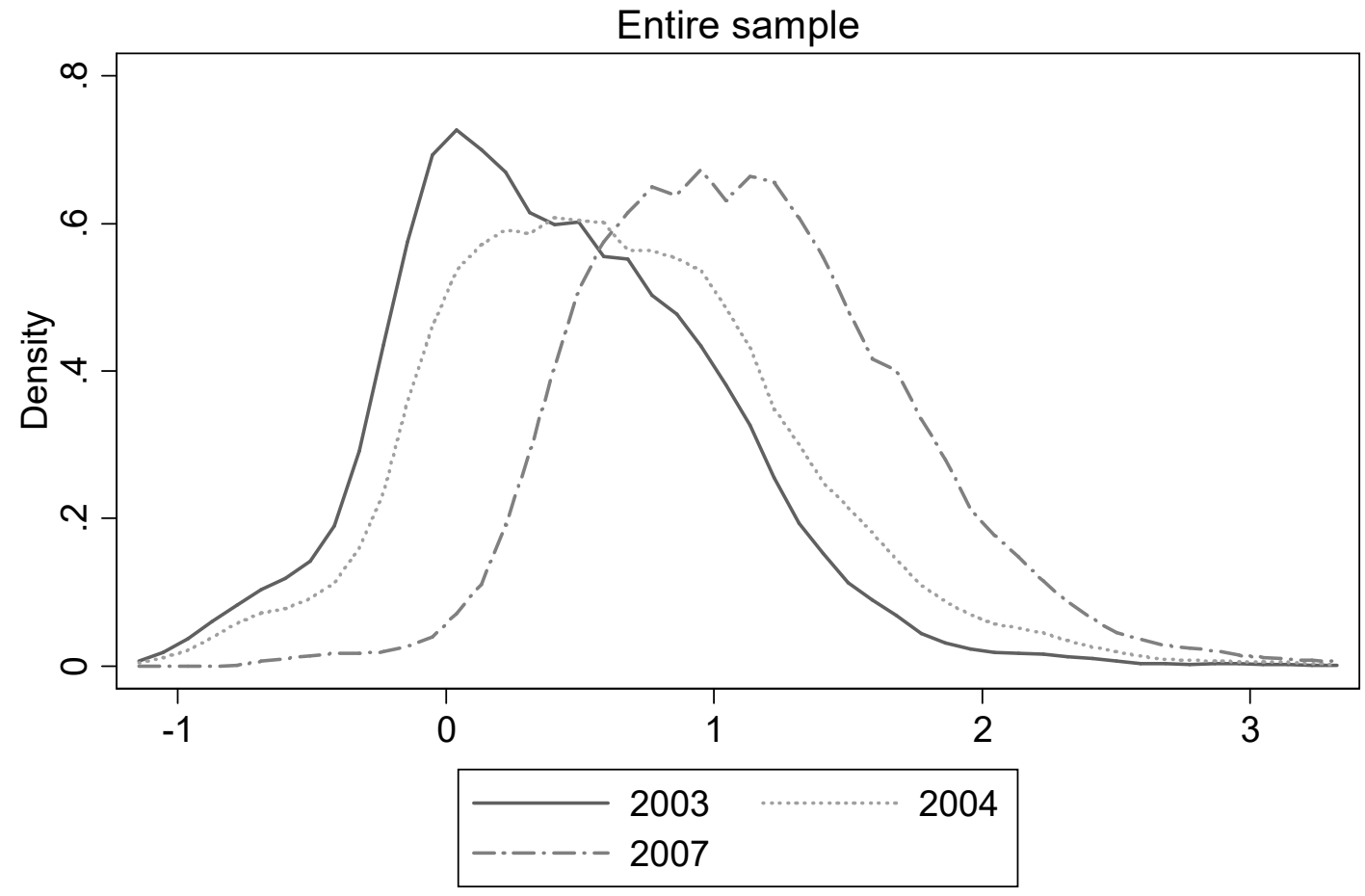

Figure 2. Log real hourly earnings by employment status - entire sample - 2003

Log real hourly earnings by employment status 2003

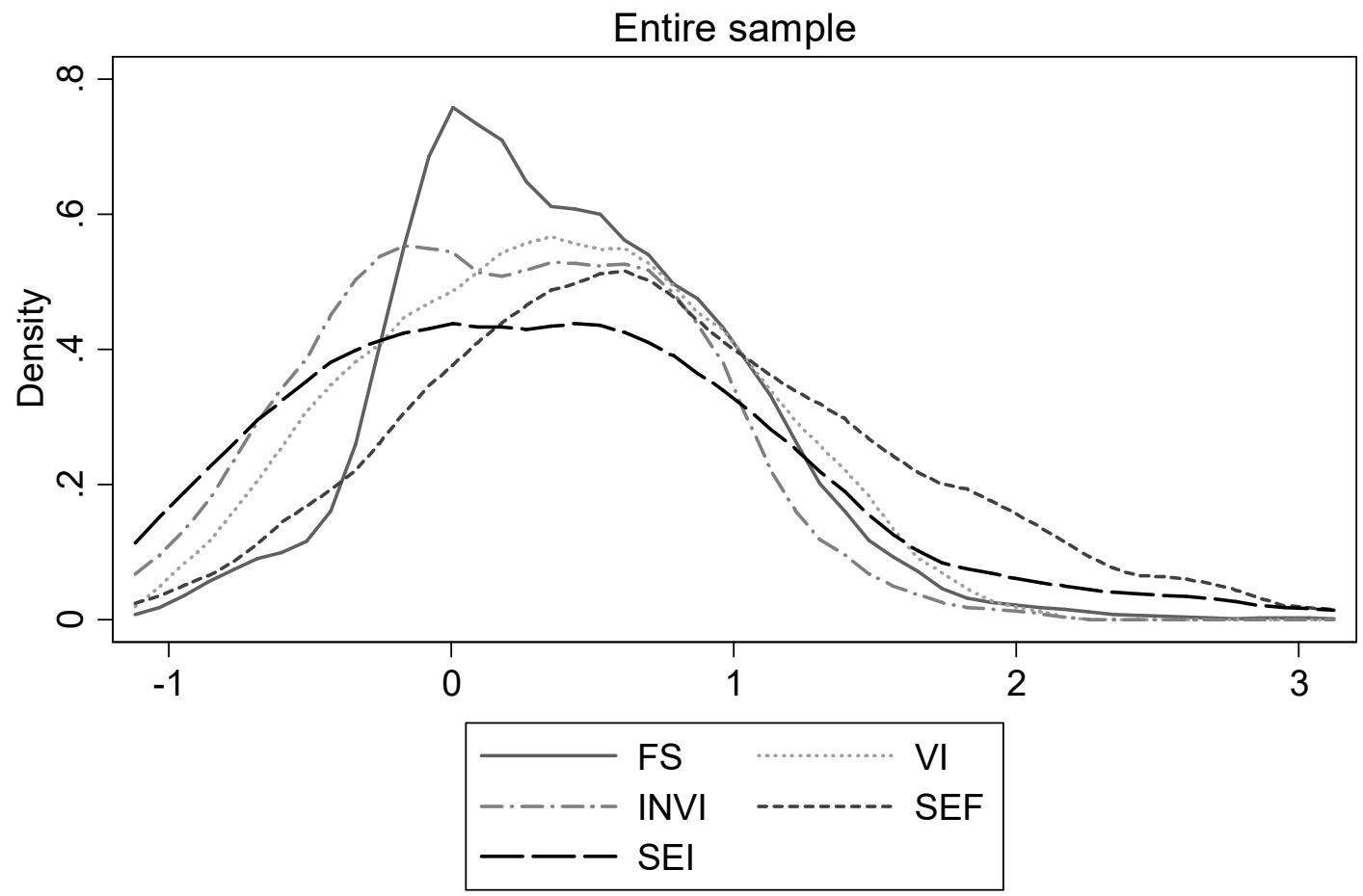


Figure 3. Log real hourly earnings by employment status - entire sample - 2004

Log real hourly earnings by employment status 2004

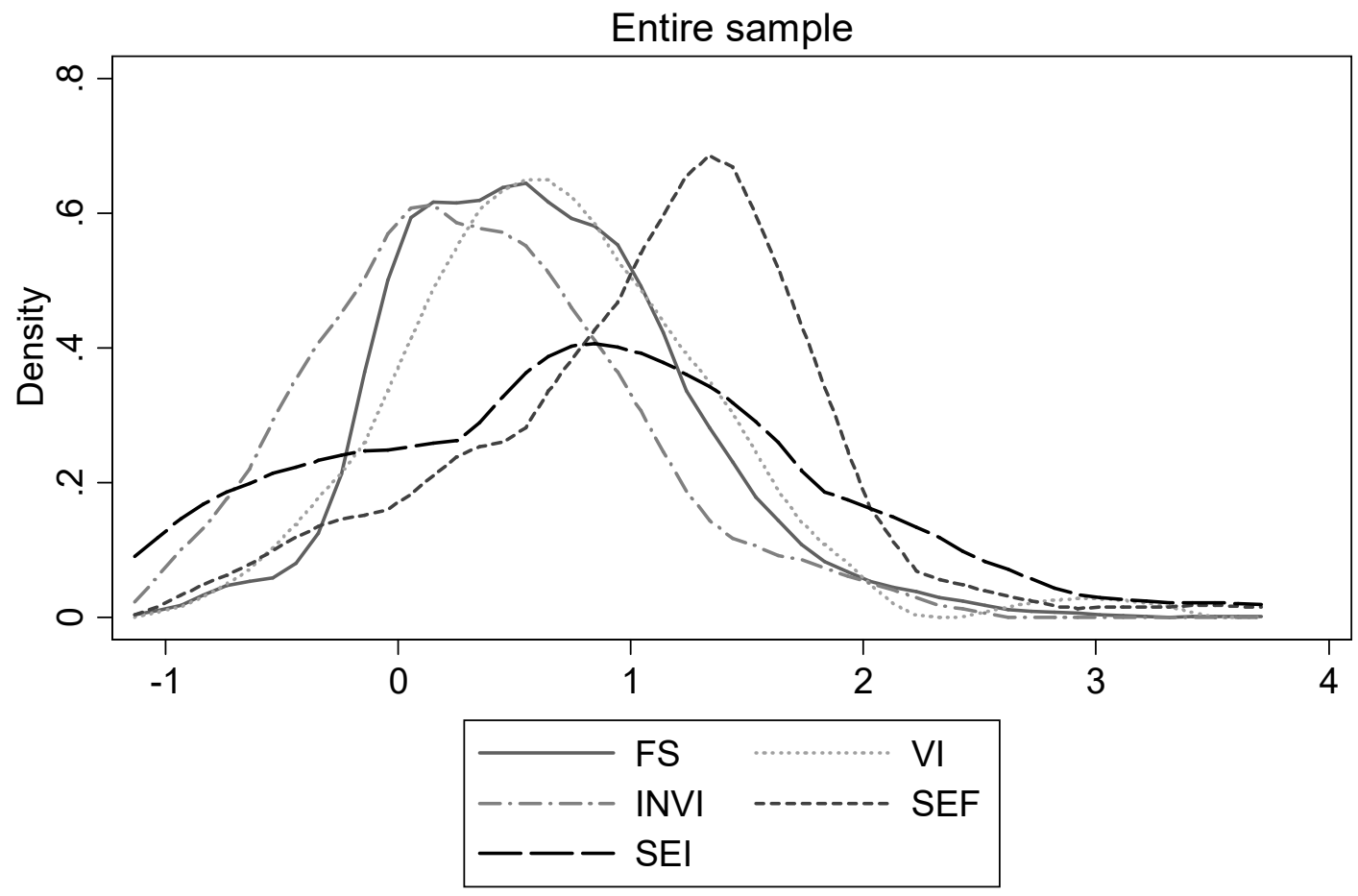

Figure 4. Log real hourly earnings by employment status - entire sample - 2007

Log real hourly earnings by employment status 2007

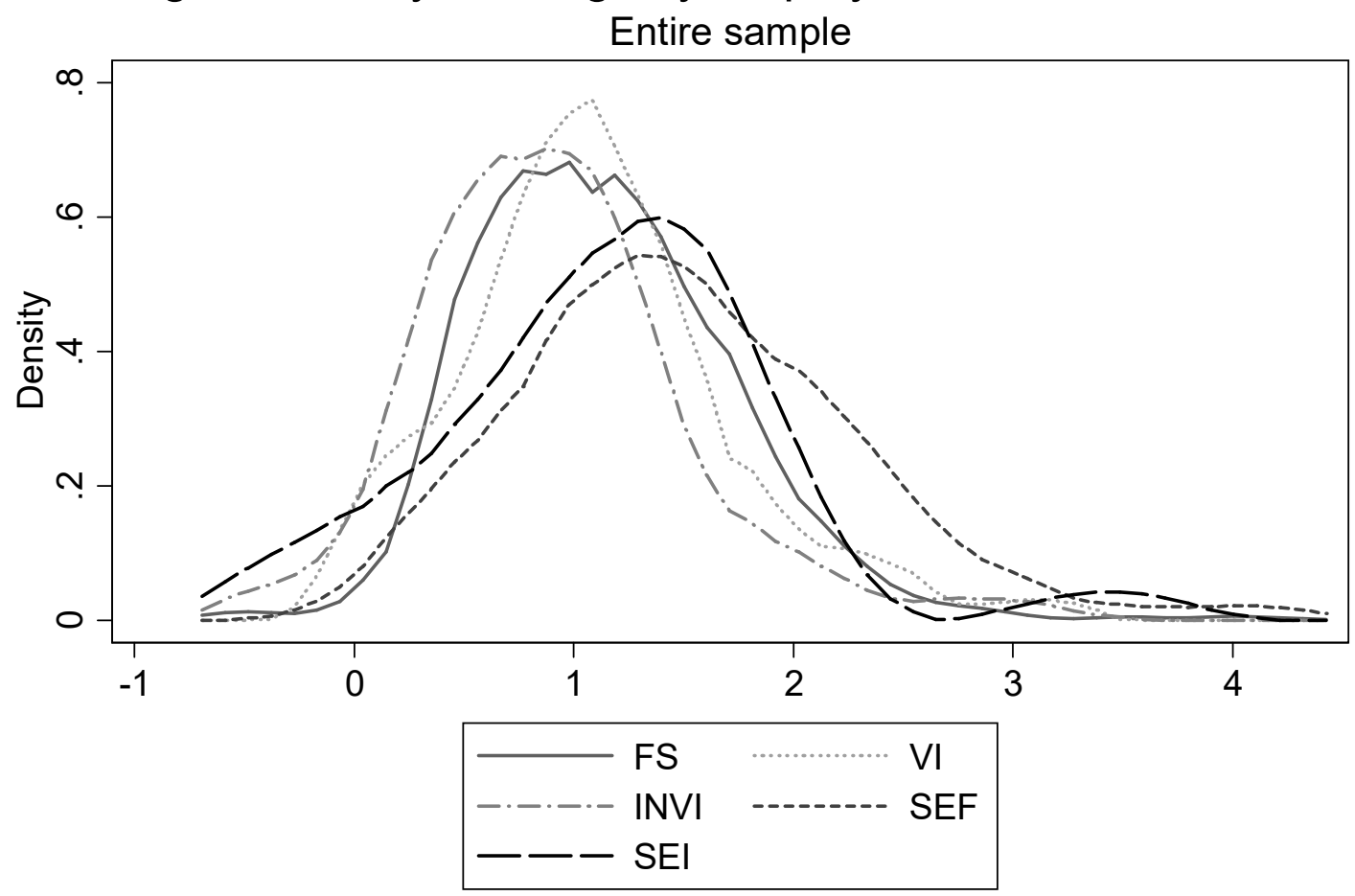

Legend: FS - Formal Salaried; VI - Voluntary Informal; INVI - Involuntary Informal; SEF Self-Employed Formal; SEI - Self-Employed Informal 
Appendix

Table A1. Employment status by sector and gender ${ }^{*}$

\begin{tabular}{|c|c|c|c|c|c|c|c|c|c|c|c|c|}
\hline & FS & $\%$ & $\mathbf{V I}$ & $\%$ & INVI & $\%$ & SEF & $\%$ & SEI & $\%$ & TOTAL & $\%$ \\
\hline \multicolumn{13}{|l|}{ Total sample } \\
\hline Agriculture, hunting and fishing & 475 & 0.07 & 12 & 0.07 & 33 & 0.08 & 16 & 0.06 & 108 & 0.39 & 644 & 0.08 \\
\hline Industry $^{\mathrm{a}}$ & 1869 & 0.27 & 21 & 0.13 & 69 & 0.16 & 11 & 0.04 & 10 & 0.04 & 1980 & 0.25 \\
\hline Construction & 288 & 0.04 & 36 & 0.22 & 55 & 0.13 & 10 & 0.04 & 64 & 0.23 & 453 & 0.06 \\
\hline Trade, Hotels and Restaurants & 668 & 0.1 & 65 & 0.4 & 195 & 0.45 & 184 & 0.65 & 45 & 0.16 & 1157 & 0.15 \\
\hline Other Services $^{b}$ & 1246 & 0.18 & 26 & 0.16 & 75 & 0.17 & 55 & 0.2 & 44 & 0.16 & 1446 & 0.18 \\
\hline Education, Health and Social protection & 1701 & 0.25 & 2 & 0.01 & 7 & 0.02 & 5 & 0.02 & 4 & 0.01 & 1719 & 0.22 \\
\hline Public administration & 570 & 0.08 & 0 & 0 & 0 & 0 & 0 & 0 & 0 & 0 & 570 & 0.07 \\
\hline Number of Observations & 6817 & & 162 & & 434 & & 281 & & 275 & & 7969 & \\
\hline \multicolumn{13}{|l|}{ Females } \\
\hline Agriculture, hunting and fishing & 203 & 0.05 & 5 & 0.06 & 14 & 0.06 & 3 & 0.02 & 56 & 0.52 & 281 & 0.07 \\
\hline Industry ${ }^{a}$ & 740 & 0.2 & 7 & 0.08 & 24 & 0.11 & 1 & 0.01 & 1 & 0.01 & 773 & 0.18 \\
\hline Construction & 66 & 0.02 & 3 & 0.04 & 3 & 0.01 & 2 & 0.02 & 4 & 0.04 & 78 & 0.02 \\
\hline Trade, Hotels and Restaurants & 434 & 0.12 & 52 & 0.62 & 136 & 0.62 & 104 & 0.81 & 24 & 0.22 & 750 & 0.18 \\
\hline Other Services $^{\mathrm{b}}$ & 623 & 0.17 & 15 & 0.18 & 36 & 0.16 & 15 & 0.12 & 21 & 0.19 & 710 & 0.17 \\
\hline Education, Health and Social protection & 1401 & 0.38 & 2 & 0.02 & 6 & 0.03 & 4 & 0.03 & 2 & 0.02 & 1415 & 0.33 \\
\hline Public administration & 269 & 0.07 & 0 & 0 & 0 & 0 & 0 & 0 & 0 & 0 & 269 & 0.06 \\
\hline Number of Observations & 3736 & & 84 & & 219 & & 129 & & 108 & & 4276 & \\
\hline \multicolumn{13}{|l|}{ Males } \\
\hline Agriculture, hunting and fishing & 272 & 0.09 & 7 & 0.09 & 19 & 0.09 & 13 & 0.09 & 52 & 0.31 & 363 & 0.1 \\
\hline Industry $^{\mathbf{a}}$ & 1129 & 0.37 & 14 & 0.18 & 45 & 0.21 & 10 & 0.07 & 9 & 0.05 & 1207 & 0.33 \\
\hline Construction & 222 & 0.07 & 33 & 0.42 & 52 & 0.24 & 8 & 0.05 & 60 & 0.36 & 375 & 0.1 \\
\hline Trade, Hotels and Restaurants & 234 & 0.08 & 13 & 0.17 & 59 & 0.27 & 80 & 0.53 & 21 & 0.13 & 407 & 0.11 \\
\hline Other Services $^{b}$ & 623 & 0.2 & 11 & 0.14 & 39 & 0.18 & 40 & 0.26 & 23 & 0.14 & 736 & 0.2 \\
\hline Education, Health and Social protection & 300 & 0.1 & 0 & 0 & 1 & 0 & 1 & 0.01 & 2 & 0.01 & 304 & 0.08 \\
\hline Public administration & 301 & 0.1 & 0 & 0 & 0 & 0 & 0 & 0 & 0 & 0 & 301 & 0.08 \\
\hline Number of Observations & 3081 & & 78 & & 215 & & 152 & & 167 & & 3693 & \\
\hline
\end{tabular}

Source: Authors' calculations based on ULMS.

* averaged over 2003, 2004 and 2007. 
a.Includes: Mining and Manufacturing.

b Includes: Energy gas water; Transportation; Financial and real estate; Other services.

Legend: FS - Formal Salaried; VI - Voluntary Informal Salaried; INVI - Involuntary Informal Salaried; SEF Self-Employed Formal; SEI - Self-Employed Informal 
Table A2. Transition matrices (women - with (A) and without (B) round-trippers): 2003-2004

\begin{tabular}{|c|c|c|c|c|c|c|c|c|}
\hline \multicolumn{9}{|c|}{ A. 2003-2004 } \\
\hline & FS & VI & INVI & SEF & SEI & $\mathbf{U N}$ & OLF & Pi. \\
\hline \multirow[t]{2}{*}{ FS } & 0.87 & 0.01 & 0.01 & 0.00 & 0.00 & 0.04 & 0.07 & 0.46 \\
\hline & 0.01 & 0.00 & 0.00 & 0.00 & 0.00 & 0.01 & 0.01 & \\
\hline \multirow[t]{2}{*}{ VI } & 0.34 & 0.22 & 0.31 & 0.03 & 0.00 & 0.03 & 0.06 & 0.01 \\
\hline & 0.09 & 0.08 & 0.08 & 0.03 & 0.00 & 0.03 & 0.04 & \\
\hline \multirow[t]{2}{*}{ INVI } & 0.22 & 0.02 & 0.47 & 0.00 & 0.04 & 0.15 & 0.11 & 0.02 \\
\hline & 0.06 & 0.02 & 0.07 & 0.00 & 0.03 & 0.05 & 0.04 & \\
\hline \multirow[t]{2}{*}{ SEF } & 0.06 & 0.03 & 0.00 & 0.79 & 0.03 & 0.00 & 0.09 & 0.01 \\
\hline & 0.04 & 0.03 & 0.00 & 0.07 & 0.03 & 0.00 & 0.05 & \\
\hline \multirow[t]{2}{*}{ SEI } & 0.06 & 0.11 & 0.00 & 0.11 & 0.44 & 0.17 & 0.11 & 0.01 \\
\hline & 0.06 & 0.07 & 0.00 & 0.07 & 0.12 & 0.09 & 0.08 & \\
\hline \multirow[t]{2}{*}{$\mathbf{U N}$} & 0.26 & 0.01 & 0.08 & 0.01 & 0.01 & 0.33 & 0.31 & 0.11 \\
\hline & 0.02 & 0.01 & 0.02 & 0.01 & 0.01 & 0.03 & 0.03 & \\
\hline \multirow[t]{2}{*}{ OLF } & 0.10 & 0.01 & 0.02 & 0.00 & 0.00 & 0.10 & 0.76 & 0.38 \\
\hline & 0.01 & 0.00 & 0.00 & 0.00 & 0.00 & 0.01 & 0.01 & \\
\hline P.j & 0.47 & 0.01 & 0.03 & 0.01 & 0.01 & 0.09 & 0.36 & \\
\hline $\mathbf{N}$ & 2,975 & & & & & & & \\
\hline
\end{tabular}

\begin{tabular}{|c|c|c|c|c|c|c|c|c|}
\hline \multicolumn{9}{|c|}{ B. 2003-2004 } \\
\hline & FS & VI & INVI & SEF & SEI & $\mathbf{U N}$ & OLF & Pi. \\
\hline \multirow[t]{2}{*}{ FS } & 0.86 & 0.01 & 0.01 & 0.00 & 0.00 & 0.04 & 0.08 & 0.46 \\
\hline & 0.01 & 0.00 & 0.00 & 0.00 & 0.00 & 0.01 & 0.01 & \\
\hline \multirow[t]{2}{*}{ VI } & 0.35 & 0.19 & 0.32 & 0.03 & 0.00 & 0.03 & 0.06 & 0.01 \\
\hline & 0.09 & 0.08 & 0.08 & 0.03 & 0.00 & 0.03 & 0.05 & \\
\hline \multirow[t]{2}{*}{ INVI } & 0.23 & 0.02 & 0.44 & 0.00 & 0.04 & 0.15 & 0.12 & 0.02 \\
\hline & 0.06 & 0.02 & 0.06 & 0.00 & 0.03 & 0.05 & 0.05 & \\
\hline \multirow[t]{2}{*}{ SEF } & 0.06 & 0.03 & 0.00 & 0.78 & 0.03 & 0.00 & 0.09 & 0.01 \\
\hline & 0.04 & 0.03 & 0.00 & 0.07 & 0.03 & 0.00 & 0.06 & \\
\hline \multirow[t]{2}{*}{ SEI } & 0.06 & 0.11 & 0.00 & 0.11 & 0.44 & 0.17 & 0.11 & 0.01 \\
\hline & 0.05 & 0.08 & 0.00 & 0.07 & 0.12 & 0.09 & 0.08 & \\
\hline \multirow[t]{2}{*}{$\mathbf{U N}$} & 0.26 & 0.01 & 0.08 & 0.01 & 0.01 & 0.31 & 0.31 & 0.11 \\
\hline & 0.03 & 0.01 & 0.01 & 0.01 & 0.01 & 0.02 & 0.03 & \\
\hline \multirow[t]{2}{*}{ OLF } & 0.10 & 0.02 & 0.02 & 0.00 & 0.00 & 0.10 & 0.76 & 0.39 \\
\hline & 0.01 & 0.00 & 0.00 & 0.00 & 0.00 & 0.01 & 0.01 & \\
\hline P.j & 0.47 & 0.01 & 0.03 & 0.01 & 0.01 & 0.09 & 0.37 & \\
\hline $\mathbf{N}$ & 2,897 & & & & & & & \\
\hline
\end{tabular}

Source: Authors' calculations based on ULMS.

Legend: FS - Formal Salaried; VI - Voluntary Informal Salaried; INVI - Involuntary Informal Salaried; SEF Self-Employed Formal; SEI - Self-Employed Informal.

Notes: Standard errors in Italic, bootstrapped with 1000 repetitions.

"Round-trippers" are persons who leave and return to the origin state over the given period.

Pi. is the relative size of a sector at the beginning of the period;

$\mathbf{P . j}$ is the relative size of a sector at the end of a period. 
Table A3. Transition matrices (men - with (A) and without (B) round-trippers): 2003-2004

\begin{tabular}{|c|c|c|c|c|c|c|c|c|}
\hline \multicolumn{9}{|c|}{ A. 2003-2004 } \\
\hline & FS & VI & INVI & SEF & SEI & $\mathbf{U N}$ & OLF & Pi. \\
\hline \multirow[t]{2}{*}{ FS } & 0.86 & 0.01 & 0.03 & 0.01 & 0.01 & 0.04 & 0.05 & 0.53 \\
\hline & 0.01 & 0.00 & 0.01 & 0.00 & 0.00 & 0.01 & 0.01 & \\
\hline \multirow[t]{2}{*}{ VI } & 0.39 & 0.30 & 0.22 & 0.09 & 0.00 & 0.00 & 0.00 & 0.01 \\
\hline & 0.10 & 0.09 & 0.09 & 0.06 & 0.00 & 0.00 & 0.00 & \\
\hline \multirow[t]{2}{*}{ INVI } & 0.31 & 0.04 & 0.39 & 0.04 & 0.08 & 0.06 & 0.08 & 0.02 \\
\hline & 0.07 & 0.03 & 0.06 & 0.03 & 0.04 & 0.03 & 0.04 & \\
\hline \multirow[t]{2}{*}{ SEF } & 0.06 & 0.00 & 0.00 & 0.79 & 0.08 & 0.06 & 0.02 & 0.02 \\
\hline & 0.03 & 0.00 & 0.00 & 0.06 & 0.04 & 0.03 & 0.02 & \\
\hline \multirow[t]{2}{*}{ SEI } & 0.09 & 0.07 & 0.09 & 0.05 & 0.49 & 0.14 & 0.07 & 0.02 \\
\hline & 0.04 & 0.04 & 0.04 & 0.03 & 0.08 & 0.06 & 0.04 & \\
\hline \multirow[t]{2}{*}{$\mathbf{U N}$} & 0.27 & 0.06 & 0.09 & 0.00 & 0.04 & 0.36 & 0.17 & 0.15 \\
\hline & 0.03 & 0.01 & 0.02 & 0.00 & 0.01 & 0.03 & 0.02 & \\
\hline \multirow[t]{2}{*}{ OLF } & 0.11 & 0.02 & 0.03 & 0.01 & 0.01 & 0.16 & 0.68 & 0.24 \\
\hline & 0.01 & 0.01 & 0.01 & 0.00 & 0.00 & 0.02 & 0.02 & \\
\hline P.j & 0.54 & 0.02 & 0.05 & 0.03 & 0.03 & 0.12 & 0.22 & \\
\hline $\mathbf{N}$ & 2,128 & & & & & & & \\
\hline
\end{tabular}

\begin{tabular}{|c|c|c|c|c|c|c|c|c|}
\hline \multicolumn{9}{|c|}{ B. 2003-2004 } \\
\hline & FS & VI & INVI & SEF & SEI & $\mathbf{U N}$ & OLF & Pi. \\
\hline \multirow[t]{2}{*}{ FS } & 0.85 & 0.01 & 0.03 & 0.01 & 0.01 & 0.05 & 0.05 & 0.51 \\
\hline & 0.01 & 0.00 & 0.01 & 0.00 & 0.00 & 0.01 & 0.01 & \\
\hline \multirow[t]{2}{*}{ VI } & 0.45 & 0.20 & 0.25 & 0.10 & 0.00 & 0.00 & 0.00 & 0.01 \\
\hline & 0.11 & 0.09 & 0.10 & 0.07 & 0.00 & 0.00 & 0.00 & \\
\hline \multirow[t]{2}{*}{ INVI } & 0.33 & 0.04 & 0.35 & 0.04 & 0.09 & 0.07 & 0.09 & 0.02 \\
\hline & 0.07 & 0.04 & 0.07 & 0.03 & 0.04 & 0.04 & 0.04 & \\
\hline \multirow[t]{2}{*}{ SEF } & 0.06 & 0.00 & 0.00 & 0.78 & 0.08 & 0.06 & 0.02 & 0.03 \\
\hline & 0.03 & 0.00 & 0.00 & 0.06 & 0.04 & 0.03 & 0.02 & \\
\hline \multirow[t]{2}{*}{ SEI } & 0.11 & 0.08 & 0.11 & 0.05 & 0.42 & 0.16 & 0.08 & 0.02 \\
\hline & 0.05 & 0.04 & 0.05 & 0.04 & 0.08 & 0.06 & 0.05 & \\
\hline \multirow[t]{2}{*}{$\mathbf{U N}$} & 0.28 & 0.06 & 0.09 & 0.00 & 0.05 & 0.35 & 0.18 & 0.15 \\
\hline & 0.03 & 0.01 & 0.02 & 0.00 & 0.01 & 0.03 & 0.02 & \\
\hline \multirow[t]{2}{*}{ OLF } & 0.11 & 0.02 & 0.03 & 0.01 & 0.01 & 0.16 & 0.67 & 0.26 \\
\hline & 0.01 & 0.01 & 0.01 & 0.00 & 0.00 & 0.02 & 0.02 & \\
\hline P.j & 0.52 & 0.02 & 0.05 & 0.03 & 0.03 & 0.12 & 0.23 & \\
\hline $\mathbf{N}$ & 2,006 & & & & & & & \\
\hline
\end{tabular}

Source: Authors' calculations based on ULMS.

Legend: FS - Formal Salaried; VI - Voluntary Informal Salaried; INVI - Involuntary Informal Salaried; SEF Self-Employed Formal; SEI - Self-Employed Informal.

Notes: Standard errors in Italic, bootstrapped with 1000 repetitions.

"Round-trippers" are persons who leave and return to the origin state over the given period.

Pi. is the relative size of a sector at the beginning of the period;

$\mathbf{P} . \mathbf{j}$ is the relative size of a sector at the end of a period. 
Table A4. Transition matrices (women - with (A) and without (B) round-trippers): 2003-2007

\begin{tabular}{|c|c|c|c|c|c|c|c|c|}
\hline \multicolumn{9}{|c|}{ A. 2003-2007 } \\
\hline & FS & VI & INVI & SEF & SEI & $\mathbf{U N}$ & OLF & Pi. \\
\hline \multirow[t]{2}{*}{ FS } & 0.76 & 0.00 & 0.01 & 0.01 & 0.01 & 0.03 & 0.17 & 0.49 \\
\hline & 0.01 & 0.00 & 0.00 & 0.00 & 0.00 & 0.01 & 0.01 & \\
\hline \multirow[t]{2}{*}{ VI } & 0.48 & 0.04 & 0.30 & 0.09 & 0.00 & 0.00 & 0.09 & 0.01 \\
\hline & 0.11 & 0.04 & 0.10 & 0.06 & 0.00 & 0.00 & 0.05 & \\
\hline \multirow[t]{2}{*}{ INVI } & 0.38 & 0.07 & 0.11 & 0.11 & 0.04 & 0.07 & 0.22 & 0.02 \\
\hline & 0.07 & 0.04 & 0.05 & 0.05 & 0.03 & 0.03 & 0.07 & \\
\hline \multirow[t]{2}{*}{ SEF } & 0.09 & 0.00 & 0.09 & 0.67 & 0.03 & 0.00 & 0.12 & 0.01 \\
\hline & 0.04 & 0.00 & 0.05 & 0.08 & 0.03 & 0.00 & 0.05 & \\
\hline \multirow[t]{2}{*}{ SEI } & 0.24 & 0.00 & 0.12 & 0.12 & 0.29 & 0.06 & 0.18 & 0.01 \\
\hline & 0.10 & 0.00 & 0.07 & 0.08 & 0.11 & 0.06 & 0.09 & \\
\hline \multirow[t]{2}{*}{$\mathbf{U N}$} & 0.39 & 0.03 & 0.08 & 0.03 & 0.03 & 0.07 & 0.37 & 0.11 \\
\hline & 0.03 & 0.01 & 0.02 & 0.01 & 0.01 & 0.02 & 0.03 & \\
\hline \multirow[t]{2}{*}{ OLF } & 0.29 & 0.02 & 0.04 & 0.02 & 0.03 & 0.07 & 0.53 & 0.35 \\
\hline & 0.02 & 0.00 & 0.01 & 0.01 & 0.01 & 0.01 & 0.02 & \\
\hline P.j & 0.53 & 0.01 & 0.04 & 0.03 & 0.02 & 0.05 & 0.32 & \\
\hline $\mathbf{N}$ & 2,332 & & & & & & & \\
\hline
\end{tabular}

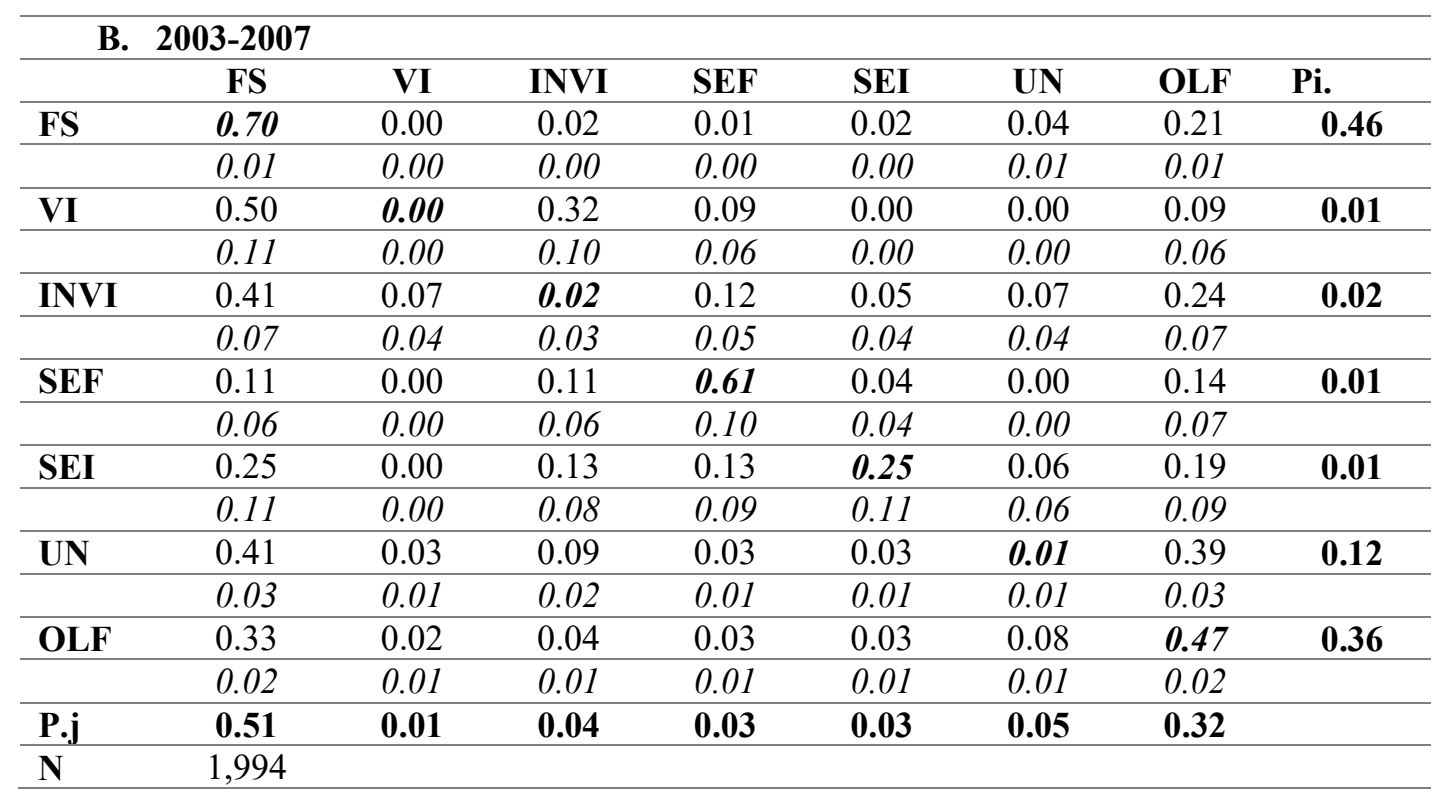

Source: Authors' calculations based on ULMS.

Legend: FS - Formal Salaried; VI - Voluntary Informal Salaried; INVI - Involuntary Informal Salaried; SEF Self-Employed Formal; SEI - Self-Employed Informal.

Notes: Standard errors in Italic, bootstrapped with 1000 repetitions.

"Round-trippers" are persons who leave and return to the origin state over the given period.

Pi. is the relative size of a sector at the beginning of the period;

$\mathbf{P} . \mathbf{j}$ is the relative size of a sector at the end of a period. 
Table A5. Transition matrices (men - with (A) and without (B) round-trippers): 2003-2007

\begin{tabular}{|c|c|c|c|c|c|c|c|c|}
\hline \multicolumn{9}{|c|}{ A. 2003-2007 } \\
\hline & FS & VI & INVI & SEF & SEI & $\mathbf{U N}$ & OLF & Pi. \\
\hline \multirow[t]{2}{*}{ FS } & 0.79 & 0.01 & 0.03 & 0.02 & 0.02 & 0.04 & 0.08 & 0.56 \\
\hline & 0.01 & 0.00 & 0.01 & 0.00 & 0.00 & 0.01 & 0.01 & \\
\hline \multirow[t]{2}{*}{ VI } & 0.38 & 0.19 & 0.10 & 0.14 & 0.10 & 0.05 & 0.05 & 0.01 \\
\hline & 0.11 & 0.09 & 0.07 & 0.08 & 0.06 & 0.05 & 0.04 & \\
\hline \multirow[t]{2}{*}{ INVI } & 0.37 & 0.00 & 0.29 & 0.00 & 0.17 & 0.09 & 0.09 & 0.02 \\
\hline & 0.08 & 0.00 & 0.08 & 0.00 & 0.07 & 0.04 & 0.05 & \\
\hline \multirow[t]{2}{*}{ SEF } & 0.16 & 0.02 & 0.02 & 0.67 & 0.02 & 0.02 & 0.07 & 0.03 \\
\hline & 0.06 & 0.02 & 0.02 & 0.07 & 0.02 & 0.02 & 0.04 & \\
\hline \multirow[t]{2}{*}{ SEI } & 0.36 & 0.05 & 0.05 & 0.09 & 0.32 & 0.09 & 0.05 & 0.01 \\
\hline & 0.11 & 0.04 & 0.05 & 0.06 & 0.10 & 0.07 & 0.04 & \\
\hline \multirow[t]{2}{*}{$\mathbf{U N}$} & 0.40 & 0.02 & 0.11 & 0.02 & 0.09 & 0.15 & 0.21 & 0.15 \\
\hline & 0.03 & 0.01 & 0.02 & 0.01 & 0.02 & 0.02 & 0.03 & \\
\hline \multirow[t]{2}{*}{ OLF } & 0.40 & 0.01 & 0.05 & 0.03 & 0.02 & 0.12 & 0.36 & 0.22 \\
\hline & 0.03 & 0.01 & 0.01 & 0.01 & 0.01 & 0.02 & 0.02 & \\
\hline P.j & 0.61 & 0.02 & 0.06 & 0.04 & 0.04 & 0.08 & 0.16 & \\
\hline $\mathbf{N}$ & 1,603 & & & & & & & \\
\hline
\end{tabular}

\begin{tabular}{|c|c|c|c|c|c|c|c|c|}
\hline \multicolumn{9}{|c|}{ B. 2003-2007 } \\
\hline & FS & VI & INVI & SEF & SEI & $\mathbf{U N}$ & OLF & Pi. \\
\hline \multirow[t]{2}{*}{ FS } & 0.71 & 0.01 & 0.05 & 0.03 & 0.03 & 0.06 & 0.11 & 0.51 \\
\hline & 0.02 & 0.01 & 0.01 & 0.01 & 0.01 & 0.01 & 0.01 & \\
\hline \multirow[t]{2}{*}{ VI } & 0.47 & 0.00 & 0.12 & 0.18 & 0.12 & 0.06 & 0.06 & 0.01 \\
\hline & 0.13 & 0.00 & 0.08 & 0.10 & 0.08 & 0.07 & 0.06 & \\
\hline \multirow[t]{2}{*}{ INVI } & 0.43 & 0.00 & 0.17 & 0.00 & 0.20 & 0.10 & 0.10 & 0.02 \\
\hline & 0.09 & 0.00 & 0.07 & 0.00 & 0.07 & 0.06 & 0.06 & \\
\hline \multirow[t]{2}{*}{ SEF } & 0.19 & 0.03 & 0.03 & 0.62 & 0.03 & 0.03 & 0.08 & 0.03 \\
\hline & 0.06 & 0.03 & 0.03 & 0.08 & 0.03 & 0.03 & 0.04 & \\
\hline \multirow[t]{2}{*}{ SEI } & 0.47 & 0.06 & 0.06 & 0.12 & 0.12 & 0.12 & 0.06 & 0.01 \\
\hline & 0.12 & 0.06 & 0.07 & 0.08 & 0.08 & 0.07 & 0.06 & \\
\hline \multirow[t]{2}{*}{$\mathbf{U N}$} & 0.44 & 0.02 & 0.12 & 0.02 & 0.10 & 0.06 & 0.23 & 0.16 \\
\hline & 0.04 & 0.01 & 0.02 & 0.01 & 0.02 & 0.02 & 0.03 & \\
\hline \multirow[t]{2}{*}{ OLF } & 0.44 & 0.02 & 0.06 & 0.03 & 0.03 & 0.14 & 0.30 & 0.25 \\
\hline & 0.03 & 0.01 & 0.01 & 0.01 & 0.01 & 0.02 & 0.03 & \\
\hline P.j & 0.57 & 0.02 & 0.07 & 0.05 & 0.05 & 0.08 & 0.17 & \\
\hline $\mathbf{N}$ & 1,279 & & & & & & & \\
\hline
\end{tabular}

Source: Authors' calculations based on ULMS.

Legend: FS - Formal Salaried; VI - Voluntary Informal Salaried; INVI - Involuntary Informal Salaried; SEF Self-Employed Formal; SEI - Self-Employed Informal.

Notes: Standard errors in Italic, bootstrapped with 1000 repetitions.

"Round-trippers" are persons who leave and return to the origin state over the given period.

Pi. is the relative size of a sector at the beginning of the period;

$\mathbf{P} . \mathbf{j}$ is the relative size of a sector at the end of a period. 
Table A6. Individuals switching employment status and sector in the three waves, entire sample and by gender

\begin{tabular}{lccccc}
\hline & $\begin{array}{l}\text { Employment } \\
\text { status } \\
\text { Switchers }\end{array}$ & $\begin{array}{c}\text { \% of people } \\
\text { initially in } \\
\text { status }\end{array}$ & $\begin{array}{l}\text { Employment } \\
\text { Status and } \\
\text { Sector } \\
\text { Switchers }\end{array}$ & $\begin{array}{c}\text { \% of people } \\
\text { initially in } \\
\text { status }\end{array}$ & $\begin{array}{l}\text { Ratio of Status } \\
\text { and Sector } \\
\text { Switchers to } \\
\text { Status } \\
\text { Switchers }\end{array}$ \\
\hline All & 247 & $4.5 \%$ & 145 & $2.7 \%$ & 0.59 \\
FS & 96 & $82.1 \%$ & 36 & $30.8 \%$ & 0.38 \\
VI & 178 & $67.2 \%$ & 94 & $35.5 \%$ & 0.53 \\
INVI & 61 & $26.5 \%$ & 27 & $11.7 \%$ & 0.44 \\
SEF & 78 & $61.4 \%$ & 37 & $29.1 \%$ & 0.47 \\
SEI & 660 & $10.7 \%$ & 339 & $5.5 \%$ & 0.51 \\
TOTAL & & & & & \\
\hline Females & 100 & $3.4 \%$ & 58 & $2.0 \%$ & 0.58 \\
FS & 47 & $82.5 \%$ & 15 & $26.3 \%$ & 0.32 \\
VI & 85 & $65.9 \%$ & 45 & $34.9 \%$ & 0.53 \\
INVI & 25 & $26.9 \%$ & 10 & $10.8 \%$ & 0.40 \\
SEF & 18 & $56.3 \%$ & 6 & $18.8 \%$ & 0.33 \\
SEI & 275 & $8.4 \%$ & 134 & $4.1 \%$ & 0.49 \\
TOTAL & & & & & \\
\hline Males & 147 & $5.9 \%$ & 87 & $3.5 \%$ & 0.59 \\
FS & 49 & $81.7 \%$ & 21 & $35.0 \%$ & 0.43 \\
VI & 93 & $68.4 \%$ & 49 & $36.0 \%$ & 0.53 \\
INVI & 36 & $26.3 \%$ & 17 & $12.4 \%$ & 0.47 \\
SEF & 60 & $63.2 \%$ & 31 & $32.6 \%$ & 0.52 \\
SEI & 385 & $13.2 \%$ & 205 & $7.1 \%$ & 0.53 \\
TOTAL & & & & & \\
\hline SOHC: & & & & & \\
\hline
\end{tabular}

Source: Authors' calculations based on ULMS.

Legend: FS - Formal Salaried; VI - Voluntary Informal Salaried; INVI - Involuntary Informal Salaried; SEF Self-Employed Formal; SEI - Self-Employed Informal. 
Table A7. Job satisfaction by employment status

\begin{tabular}{lrrr}
\hline & $\mathbf{2 0 0 3}$ & $\mathbf{2 0 0 4}$ & $\mathbf{2 0 0 7}$ \\
\hline Formal Salaried & 73.1 & 79.0 & 66.9 \\
Voluntary Informal & 60.3 & 60.2 & 56.6 \\
Involuntary Informal & 55.7 & 63.3 & 37.3 \\
Self-Employed Formal & 78.4 & 79.2 & 79.4 \\
Self-Employed Informal & 56.1 & 48.8 & 42.2 \\
\hline
\end{tabular}

Note: individuals are classified as "satisfied" if they report to be rather satisfied or above.

Table A8. Life satisfaction by labor market status

\begin{tabular}{lrrr}
\hline & $\mathbf{2 0 0 3}$ & $\mathbf{2 0 0 4}$ & $\mathbf{2 0 0 7}$ \\
\hline Formal Salaried & 47.0 & 61.0 & 43.5 \\
Voluntary Informal & 50.6 & 57.5 & 31.3 \\
Involuntary Informal & 37.1 & 45.1 & 31.7 \\
Self-Employed Formal & 56.8 & 71.2 & 59.2 \\
Self-Employed Informal & 42.5 & 37.2 & 30.7 \\
Unemployed & 29.6 & 31.3 & 21.6 \\
Out of Labor Force & 50.5 & 56.0 & 42.7
\end{tabular}

Note: individuals are classified as "satisfied" if they report to be rather satisfied or above.

Source: ULMS. 


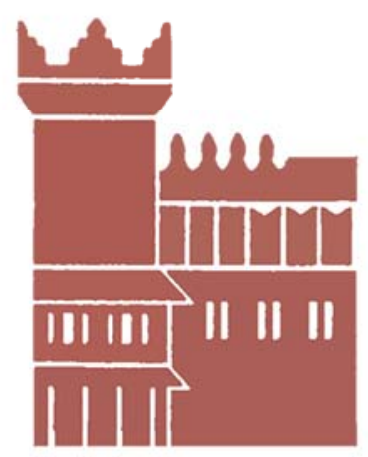

Alma Mater Studiorum - Università di Bologna DEPARTMENT OF ECONOMICS

Strada Maggiore 45

40125 Bologna - Italy

Tel. +39051 2092604

Fax +390512092664

http://www.dse.unibo.it 